Illinois State University

ISU ReD: Research and eData

Theses and Dissertations

7-15-2020

\title{
Social Support, Mental Health Problems, And Rule Infractions: A Study Of Female Inmates
}

\author{
Suraiya H. Shammi \\ Illinois State University, shammidu89@gmail.com
}

Follow this and additional works at: https://ir.library.illinoisstate.edu/etd

Part of the Criminology and Criminal Justice Commons

\section{Recommended Citation}

Shammi, Suraiya H., "Social Support, Mental Health Problems, And Rule Infractions: A Study Of Female Inmates" (2020). Theses and Dissertations. 1308.

https://ir.library.illinoisstate.edu/etd/1308

This Thesis is brought to you for free and open access by ISU ReD: Research and eData. It has been accepted for inclusion in Theses and Dissertations by an authorized administrator of ISU ReD: Research and eData. For more information, please contact ISUReD@ilstu.edu. 


\section{SOCIAL SUPPORT, MENTAL HEALTH PROBLEMS, AND RULE INFRACTIONS:}

\section{A STUDY OF FEMALE INMATES}

\section{SURAIYA H. SHAMMI}

\section{Pages}

Currently there are few studies that solely focused on female inmates and their mental health problems. There is huge lack of in-depth examination on the impact of social support variables on overall rule infractions. Using a multilevel analysis, this study analyzed the moderation effect of social support variables on rule infractions among female inmates $(n=2,930)$ from the 2004 Survey of Inmates of State Correctional Facilities in the United States. Findings suggest that almost $55 \%$ of the sample suffered from mental health problems where female inmates with mental health problems reported significantly higher rates of minor rule infractions (78\%). Also, the results found that with high level of stress and unstable social support inmates tend to involve with more substance-related rule infractions. The findings suggest for more research to understand broader implications of social support on mental health conditions of female inmates.

KEYWORDS: Female inmates, social support, rule infractions, mental illness, mental health problems 
SOCIAL SUPPORT, MENTAL HEALTH PROBLEMS, AND RULE INFRACTIONS:

A STUDY OF FEMALE INMATES

SURAIYA H. SHAMMI

A Thesis Submitted in Partial

Fulfillment of the Requirements

for the Degree of

MASTER OF SCIENCE

Department of Criminal Justice Sciences

ILLINOIS STATE UNIVERSITY 
(C) 2020 Suraiya H. Shammi 
SOCIAL SUPPORT, MENTAL HEALTH PROBLEMS, AND RULE INFRACTIONS:

A STUDY OF FEMALE INMATES

SURAIYA H. SHAMMI

COMMITTEE MEMBERS:

Brent Teasdale, Chair

Dawn Beichner

Philip Mulvey 


\section{ACKNOWLEDGMENTS}

Frist of all, I would like to express immense gratitude to my esteemed thesis chair Prof. Brent Teasdale, for his relentless support and continuous guidance. Thank you for believing in me and giving me this wonderful opportunity to work under your kind mentorship. My heartiest gratitude also goes to my dearest committee members Profs. Dawn Beichner and Philip Mulvey. Thank you for supporting me with all your candid and wise directions whenever I needed. I am

forever grateful to Illinois State University and Criminal Justice Sciences department for making me who I am today.

Thank you to my beloved family, Mom, Dad, Auve, Sumi, Rumi, Rafi, Saima, Zowee and Raad for all the staunch support and unconditional love throughout my graduate studies. Special thanks to my dad for watching me over from heaven and giving me the strength to stay

focused at my work. Finally, thanks to my graduate cohort members, Jake and Alena, for always being there. It's an honor to have walked this path with you. 


\section{CONTENTS}

Page

ACKNOWLEDGMENTS

CONTENTS

TABLES

CHAPTER I: INTRODUCTION 1

$\begin{array}{ll}\text { Background } & 2\end{array}$

Statement of the Problem 3

CHAPTER II: LITERATURE REVIEW 6

Defining Rule Infractions $\quad 6$

$\begin{array}{ll}\text { Gender differences and rule infractions } & 7\end{array}$

$\begin{array}{ll}\text { Sentence length and rule infractions } & 8\end{array}$

Theoretical Orientation: Importation Theory 9

Theoretical Orientation: Deprivation Theory 12

Prevalence of Mental Health Challenges among Female Inmates 13

Prison Environment and Lack of Available Resources 14

Coping Strategies for Inmates with Mental Health Problems 15

Prevalence of Rule Infractions among Female Inmates 17

Stress, Mental Illness, and Role of Social Support Moderators for Coping 17

$\begin{array}{ll}\text { Role of stress model } & 18\end{array}$

$\begin{array}{lr}\text { Role of social support moderators } & 18\end{array}$

Social Support and Rule Infractions among Female Inmates with Mental Illness 19

$\begin{array}{ll}\text { Social support resources } & 20\end{array}$ 
Social Support and Its Impact on Mental Health Problems 22

$\begin{array}{ll}\text { Summary } & 23\end{array}$

$\begin{array}{ll}\text { Current Study } & 23\end{array}$

CHAPTER III: METHODOLOGY 26

$\begin{array}{ll}\text { Data } & 26\end{array}$

Sample 26

First Stage of Sampling $\quad 27$

Second Stage of Sampling $\quad 28$

$\begin{array}{lr}\text { Confidentiality } & 28\end{array}$

$\begin{array}{lr}\text { Measures } & 29\end{array}$

Dependent Variable: Rule Infractions

Independent Variable: Mental Illness

Moderating Variable: Social Support

$\begin{array}{ll}\text { Control Variables } & 35\end{array}$

$\begin{array}{ll}\text { Data Analysis } & 37\end{array}$

$\begin{array}{ll}\text { Missing Data } & 38\end{array}$

CHAPTER IV: RESULTS

Univariate Analysis: Sample Description 39

$\begin{array}{ll}\text { Bivariate Analysis: Crosstabs } & 40\end{array}$

$\begin{array}{ll}\text { Bivariate Analysis: t-tests } & 46\end{array}$

Multivariate Analysis: Logistic Regression Model 48

CHAPTER V: DISCUSSION

Policy Implications $\quad 56$ 
Recommendations 


\section{TABLES}

Table

Page

1. Variables

2. Descriptive Statistics 39

3. Crosstabs: Major Rule Infractions and Independent Variables 41

4. Crosstabs: Minor Rule Infractions and Independent Variables 43

5. Crosstabs: Substance-Related Rule Infractions and Independent Variables 45

6. Independent Sample T-Test (Major Rule Infractions and Independent

Variables)

7. Independent Sample T-Test (Minor Rule Infractions and Independent

Variables)

8. Independent Sample T-Test (Substance-Related Rule Infractions and

Independent Variables)

9. Logistic Regression: Major, Minor and Substance Related Rule Infractions 49

10. Logistic Regression Model for Major Rule Infractions Split by Mental Health

Problems

11. Logistic Regression Model for Minor Rule Infractions Split by Mental Health Problems

12. Logistic Regression Model for Substance-Related Rule Infractions Split by Mental Health Problems 


\section{CHAPTER I: INTRODUCTION}

Many studies have widely investigated the higher prevalence of mental health problems, among the incarcerated population (Bronson \& Berzofsky, 2017; Fazel, Hayes, Bartellas, Clerici, \& Trestman, 2016; Flanagan, 1983; Fogel \& Martin, 1992; Goffman, 1961; Hurley \& Dunne, 1991; James \& Glaze, 2006; Lindquist \& Lindquist, 1997; Steadman, Osher, Robbins, Case, \& Samuels, 2009; Teplin, 1990; Torrey, Kennard, Eslinger, Lamb, \& Pavle, 2010; Travis, Western, \& Redburn, 2014).

Currently, there are 231,000 (Kajstura, 2019) incarcerated female inmates in the United States, which represents a doubling in number since $2012(108,866)$ (Carson \& Golinelli, 2012). According to the recent DOJ report, more female inmates $(66 \%)$ than male inmates $(35 \%)$ have found with a history of mental health problems (Bronson \& Berzofsky, 2017). This poses serious concern for mental health problems and their consequences for female inmates.

Indeed, inmates suffering from various mental illness are faced with numerous challenges in adjusting to the prison environment (Adams, 1980; Toch \& Adams, 1986). Due to the unmet treatment needs of mental health problems, prisoners are less likely to behave by the rulebook, which results in rule violations (Fellner, 2006; Negy, Woods, \& Carlson, 1997). Therefore, the relationship between inmate's mental illness and rule infractions have received a great deal of attention by current studies (Felson, Silver, \& Remster, 2012; Fellner, 2006;

Houser, Belenko, \& Brennan, 2012; James \& Glaze, 2006; Krelstein, 2002; Metzner, 2002; Stewart \& Wilton, 2014; Steiner, Butler, \& Ellison, 2014) Also, there is a long history of studies establishing this correlation which showed strong empirical associations between mental health problems and rule infractions (Adams, 1986; Flanagan, 1983; Fogel et al., 1992). 


\section{Background}

Challenges for female inmates: Female inmates go through different levels of adjustment to major life events, which significantly impacts their incarceration experience (Gover, Perez, \& Jennings, 2008; Jiang \& Winfree, 2006; Negy, Woods, \& Carlson, 1997; Tewksbury, Connor, \& Denney, 2014;). Notably, female inmates face numerous problems while being incarcerated, whether resulting from their lives before imprisonment (importation) or as a consequence of their incarceration (deprivation). Separation from family and children, loss of social support, fear of losing custody of their children, lengthy sentences, and finding themselves in a strange, new environment all may profoundly impact female inmates in a different way than these variables impact male inmates (Bloom \& Covington, 2008; DeHart, Lynch, Belknap, DassBrailsford, \& Green, 2014; Green, Miranda, Daroowalla, \& Siddique, 2005; Pollock, 2002;). Thus, several studies supported a close connection between life experiences and background characteristics of female inmates to prison rule infractions (Owen, Wells, \& Pollock, 2017; Steiner, Wright \& Toto; 2019).

Mental health and rule infractions among female inmates: According to James \& Glaze's 2006 study, almost 73\% of female inmates exhibited signs of a mental health problems; this is significantly greater than for male inmates (55\%). A recent Bureau of Justice (BJS) report found $36.9 \%$ of inmates reported having a major depressive disorder who were already experiencing mental health disorders. Also, the report found several mental health indicators were prevalent among inmates, including post-traumatic stress disorder (PTSD) (13\%), anxiety disorder (12\%), personality disorder (13\%), and other psychotic disorders $(9 \%)$ (Bronson \& Berzofsky, 2017). 
Moreover, female inmates with mental health problems were found to be involved with more rule infractions than those who do not demonstrate such symptoms (Celinska \& Sung, 2014; Mccorkle, 1995; Negy, Woods, \& Carlson, 1997; Steiner \& Wooldredge, 2009; Steiner, Wright, \& Toto, 2019). In contrast, many of the studies suggest that compared to male inmates, females adjust more easily to prison and tend to engage in less violence resulting in nonviolent rule infractions than violent rule infractions (Craddock, 1996; Jiang \& Winfree, 2006; Steiner, Wright, \& Toto, 2019; Steiner \& Wooldredge, 2009).

\section{Statement of The Problem}

Inmates with mental health problems were more likely to be charged with disciplinary infractions (58\%) than those without mental health problems (43\%) (James \& Glaze, 2006). Since prison life requires a different level of versatility, individuals with exceptional personal skills are best situated to cope with those rules (Negy, Woods, \& Carlson, 1997). Specifically, inmates who have mental illness, drug abuse, or previous physical abuse can be expected to experience more struggles while adjusting to the prison routine (Toch \& Adams, 1986). According to Houser and Belenko (2012), signs of undiagnosed mental illness can be miscomprehended as rule-violating behavior by correctional officers and may aggravate the severity of disciplinary sanctions when imposed. Fellner (2006) asserted that formal and informal prison rules and codes of conduct could become difficult to coordinate with people who possess the need for specialized support.

Many female prisoners enter the criminal justice system with mental health problems including depression, anxiety, post-traumatic stress disorder (PTSD), substance or drug use disorders (Bloom, Chesney, \& Owen, 1994; Browne, Miller, \& Maguin, 1999; Covington \& Bloom, 2003; Flanagan, 1983; James \&Glaze, 2006; Jordan, Schlenger, Fairbank, \& Cadell, 
1996; Warren, 2003). Coping with the prison environment becomes a difficult challenge for these vulnerable populations (Flanagan, 1983; Houser \& Belenko, 2015; Kuo \& Zhao, 2019), where social support variables were found to be helpful for a smoother transition into prison life (Jiang, \& Winfree, 2006; Jiang, Fisher-Giorlando, \& Mo, 2005).

A number of studies found social support variables to influence the rule infractions by lessening stress in the prison environment (Jiang \& Winfree, 2006; Tewksbury et al.,2014; Steiner \& Wooldredge, 2009; Steiner, Wright \& Toto, 2019). Thus, social support reduces the negative emotional experience in a stressful situation, by producing positive behavioral responses (Kawachi \& Berkman, 2001).

On the contrary, the unavailability of social support variables can result in more stress and anxiety. Thus, being unable to cope with the prison environment along with various mental health problems, female inmates often end up with rule violating behavior (Fellner, 2006; Jiang \& Winfree, 2006; Steiner \& Wooldredge, 2009).Although a majority of studies supporting the association between rule infractions and mental health problems were based on male-only samples or samples where the rule infractions were committed by both males and females with the majority being male inmates (Craddock,1996; Celinska \& Sung, 2014; Wooldredge, Griffin, \& Pratt, 2001; Gover, Perez, \& Jennings, 2008; Steiner \& Wooldredge, 2008; Tischler \& Marquart, 1989), it is important to investigate the unique experiences of female inmates. To date, few studies investigated samples of female inmates only (Houser, Belenko, \& Brennan, 2012; Reidy, Cihan, \& Sorensen, 2017; Steiner, Wright, \& Toto, 2019).

Therefore, this study aims to represent the unique associations of female inmates, as female's understanding of life events are different than males (Browne, Miller, \& Maguin, 1999; Pollock, 2002). Also, studies have highly emphasized the need for social support variables for 
female inmates than male inmates (Mancini, Baker, Sainju, Golden, Bedard, \& Gertz, 2016; Pollock, 2002). This study aims to investigate the contribution of social support moderators for defining the association between rule infractions and mental health problems among female inmates. In doing so, this study will provide a meaningful interpretation of rule violating behaviors tied to the specific attributes for female inmates only. 


\section{CHAPTER II: LITERATURE REVIEW}

This chapter provides a review of the literature on rule infractions among female inmates who have mental health problems. The researcher first discusses the definition and prevalence of rule infractions among inmate populations. The study explores rule infractions through the lens of the importation and deprivation model to build a theoretical framework for the study. The stress process model will be presented as a tool for understanding the connection between rule infractions and the presence of mental health problems among female inmates. Finally, the role of social support will be addressed as a moderating variable for the association between rule infractions and mental health problems among female inmates.

\section{Defining Rule Infractions}

Many scholars have defined rule infractions as the institutional rule-breaking behavior of an inmate (Kruttschnitt \& Gartner, 2005; Merbitz, Jain, Good, \& Jain, 1995; Steiner \& Wooldredge, 2009, Tewksbury, Connor \& Denney, 2014; Tahamont, 2019;). For each rule infraction, inmates are typically charged with a disciplinary ticket (Merbitz et al., 1995). Because the main goal for the prison system is to provide safety for all prison staff and inmates by controlling rule infractions, inmates are expected to abide by the institutional code. Any deviations from the defined guidelines are viewed as rule infractions. According to Sykes (1958), disciplinary actions in prison help to determine a line between acceptable behaviors and inappropriate ones, for those in the process of adapting to the prison environment. Therefore, any behavior that does not fit into the standard of the prison system is labeled as rule infractions.

Prison rule-breaking behavior can include nonviolent or minor rule infractions (e.g., failing to follow sanitary regulations) and serious or major ones (e.g., possessing a weapon) (Flanagan, 1983; Merbitz et al., 1995; Poole \& Regoli, 1979; Stephen, 1990; Tewksbury, Connor 
\& Denney, 2014; Tahamont, 2019). According to Tahamont (2019), "examples of serious rules violation reports include any activity that would qualify as a crime outside the prison; as well as, hideout, preparation to escape, or possession of escape paraphernalia; possession of contraband or controlled substances; bartering; manufacture of alcohol; and refusing to work or participate in programs" (p.783). Some inmates may commit a few severe rule violations, while others may commit several minor infractions. Any rule infraction despite the frequency and severity poses a high concern for the prison administration (Petersilia et al., 1980).

\section{Gender differences and rule infractions}

Several studies have acknowledged the differences between male and female inmates in rates of rule infractions (Craddock, 1996; Celinska \& Sung 2014; Gover, Perez, \& Jennings, 2008; Harer \& Langan, 2001; MacKenzie \& Goodstein 1985; McClellan 1994). According to Craddock (1996), different levels of rule infractions between male and female inmates are the indicators of how they adjust to the prison environment. According to Jiang and his colleagues' (2005) study, nonviolent, or minor rule violations (e.g., abusive words, hygiene violations) were found to be higher among female inmates. On the other hand, serious or major rule violations such as possession of a weapon, assaults, and attempt to escape were found to be higher among male inmates. Celinska and Sung (2014) found that female inmates committed rule violations less frequently than male inmates. Their result showed that almost $45 \%$ of all surveyed inmates (a total sample of 18,185 inmates) had been found guilty of breaking prison rules. The prevalence of rule infractions among female inmates was $38.3 \%$ compared to male inmates (47.6\%). Harer and Langans (2001) found similar results using a sample of 24,765 females and 177,167 male inmates. The rate of serious violence was lower among females than males $(2.77 \%$ 
vs. $18.5 \%)$. Whereas, nonserious offenses were similar for both sexes $(3.1 \%$ for females, and $3.5 \%$ for males).

\section{Sentence length and rule infractions}

Earlier researchers showed a close association between rule infractions and an inmate's sentence length (Bales \& Miller, 2012; Flanagn, 1983; MacKenzie and Goodstein, 1985;

MacKenzie, Robinson, and Campbell,1989; Reidy \& Sorensen, 2018; Steiner \& Wooldredge, 2008; Toch \& Adams, 2002; Thompson \& Loper, 2005; Toman, Cochran, Cochran, \& Bales, 2015). Casey-Acevedo and Bakken (2001) found that long-term female inmates were more violent and committed a higher rate of infractions compared to those with short-term sentences. According to MacKenzie and colleagues (1989), female inmates deal with more situational anxiety as the prison sentence lengthens. They start to feel bored and worry about jobs and family. To cope with situations, females are willing to engage in meaningful relationships, often called families (Jiang \& Winfree, 2006; Mancini et al., 2016; Marcum, Hilinski-Rosick, \& Freiburger, 2014; Zingraff, 1980), whereas males are more focused on doing their own time in prison, rather than involving in interpersonal ties (Jiang \& Winfree; 2006; Zingraff, 1980;). As a result, initially prison families work as the support system for female inmates, but in the long term, they start to depend less on prison families and start to show more rule infractions as anxiety and depression rise.

On the contrary, studies showed a positive association between long term prison sentences and lower rates of infractions among male inmates (Flanagan, 1983; Toch \& Adams, 2002; Zamble, 1992). While controlling demographic variables such as age, Flanagan (1983) found that the annual rate of disciplinary infractions was lower among inmates serving longer sentences than short term inmates. Supporting Flanagan's study, MacKenzie and Goodstein 
(1985) argued that male inmates with lengthier prison sentences showed signs of adjustment over time and tended to report less emotional stress as their sentences progressed.

\section{Theoretical Orientation: Importation Theory}

Importation theory focuses on prisoners' pre-incarceration characteristics such as norms, beliefs, values, and antisocial behavior, which are imported into the prison during incarceration (Irwin \& Cressey, 1962). Previous research has established that participation in and experience with criminal behaviors within a community does not cease after incarceration (Cihan, Davidson, \& Sorensen, 2017; Irwin \& Cressey, 1962; Stacer, Solinas, \& Saunders, 2015; Walters, 2015). In support of the importation model, Tewksbury and colleagues (2014) argued that many inmates continue to be involved in rule violating activity while in prison, which can be linked to their pre-incarceration criminal activities. This assertion correlates with the idea that inmates carry their pre-incarceration characteristics into prison with them (importation), and these characteristics can be associated with prison rule violations. Although no particular set of background characteristics perfectly predicts prison misconduct consistently across studies, many studies have found strong associations between rule infractions and pre-incarceration characteristics (Houser, Belenko, \& Brennan, 2012; Irwin, 1981; Steiner \& Wooldredge, 2009; Sorensen, Wrinkle, \& Gutierrez, 1998;). For instance, inmate's previous employment status, race, marital status, and age have been widely considered as pre-incarceration elements that increase the risk of prison misconduct (Carroll 1974; Flanagan, 1983; Irwin 1970; Irwin \& Cressey 1962).

Age: Age has been found to be the most consistent predictor for both minor and significant rule violations (Cunningham \& Sorensen, 2006; Flanagan, 1983; Griffin \& Hepburn, 2006; Kuanliang, Sorensen, \& Cunningham, 2008; Steiner \& Wooldredge, 2008; Wooldredge, 
Griffin, \& Pratt, 2001; Welsh, McGrain, Salamatin, \& Zajac, 2007). The existing studies have consistently shown the reverse relationship between age and rule infractions. For example; As Simon (1993) observed: disciplinary infractions are more prevalent among younger inmates than the older ones. Sorensen and Cunningham's (2010) finding also confirms Simon's argument, since they found that the likelihood of rule infractions reduces by $5 \%$ for each year of increase in age. According to Flanagan (1983), inmates under 25 years were the group most likely to engage in rule infractions. Which explains that as age increases, rule infractions decrease.

Race: Race as a demographic factor has been widely examined with inmates' participation in rule-breaking behavior (Camp, Gaes, Langan, \& Saylor, 2003; Gendreau, Goggin \& Law, 1997; Harer \& Steffensmeier,1996). According to Gendreau, Goggin, and Law (1997), race was found to be the most widely used predictor of prison rule violations. According to Wooldredge, Griffin, and Pratt (2001), nonwhites are more likely to be engaged in prison misconduct, while Camp, Gaes, Langan, and Saylor (2003) found that individuals of other races did not differ from Whites in their likelihood of prison rule violation. Moreover, researchers have also found that Whites are less likely to commit serious/violent rule infractions than other races (Jiang \& Winfree, 2006; Bales \& Miller, 2012; Jiang, Fisher-Giorlando, \& Mo, 2005; Morris, Longmire, Buffington-Vollum, \& Vollum, 2010; McReynolds \& Wasserman, 2008; Steiner \& Wooldredge, 2008;). Though Harer and Steffensmeier's study (1996) did not find any significant variation between Blacks and Whites for alcohol/drug misconduct, Blacks were reportedly found to be more than twice as likely to be guilty of violent rule violations. Poole and Regoli (1980) have found biases in reporting rule infractions when it comes to race. They found that Black people were more heavily reported for rule infractions than any other race. Hence, race is a 
critical variable which needs to be carefully examined while explaining an inmate's adjustment to prison life.

Marital Status: Most studies found marital status was an important predictor of rule infractions (Jiang, Fisher-Giorlando, \& Mo, 2005; Jiang \& Winfree 2006; Myers \& Levy, 1978; Wooldredge, Griffin, \& Pratt, 2001). According to Jiang and colleagues' (2005) study, being a married inmate reduced the anticipated rule infractions by $14 \%$. According to Wooldredge, Griffin, \& Pratt (2001), the odds of misconduct are lower among inmates who perceive they have more to lose by engaging in deviant behavior, which is an important consideration for married inmates. Jiang and Winfree (2006) found a 23\% decline in rule infractions among married inmates compared to unmarried inmates. Overall, the research shows a significant correlation between marital status and rule infractions.

History of drug use: According to the importation theory, prison rule violations, especially substance use infractions, are found to be correlated with pre incarceration drug use history (Irwin, 1970; Jiang, Fisher-Giorlando, \& Mo, 2005; MacDonald, 1999; Sykes 1958). The theory suggests that inmates bring the history of drug use into the prison, meaning those habituated to drug use would carry on their use even in prison. In fact, according to a recent Bureau of Justice (BJS) report, more female prisoners (47\%) used drugs before the month of the current offense than male prisoners (38\%) (Bronson, Stroop, Zimmer, \& Berzofsky, 2017). James and Glaze's 2006 study found that $75 \%$ of female prisoners met the measures of concurrently experiencing both mental health problems and drug abuse. Sykes's (1958) explained, while confronting a stressful situation in prison, there is a high chance that individuals go back to their previous habit of using drugs to adapt to the stressful environment. Therefore, 
while analyzing rule violating behaviors, previous history of substance use can be insightful to establish risk for rule infractions, among female inmates.

\section{Theoretical Orientation: Deprivation Theory}

Apart from pre-incarceration characteristics, prison life itself can trigger rule violating behavior among inmates, since they get deprived of freedoms and social supports. According to Tewksbury, Connor, and Denney (2014: 206), “deprivation theory refers to situational factors present within a correctional institution that can impact an inmate's adjustment." Sykes (1958), one of the key proponents of the deprivation theory, linked prison conditions with rule violating behavior. As Sykes (1958) states, loss of freedom, loss of access to existing goods and services, loss of heterosexual relationships, loss of self-governance, and loss of private security brings the "pains of imprisonment" (pp. 63-78). While experiencing the pains of imprisonment, inmates develop a subculture which creates higher levels of anxiety and distress among inmates (Cao, Zhao, \& Dine, 1997; Goffman, 1961; Harer \& Steffensmeier, 1996; McCorkle, Miethe, \& Drass, 1995; Schnittker, Massoglia \& Uggen, 2012; Wright, 1991), which can increase rule violating behaviors.

Deprivation theory asserts that an inmate's behavior is shaped by the experiences of the pains of imprisonment and thereby how inmates prioritize their needs in prison. In fact, Sykes (1958) found that inmates choose various roles that were shaped by the way an inmate prioritized their needs. Also, the selection of roles gets influenced by the degree to which a particular environmental characteristic inhibits an inmate's satisfaction of each need. This can lead to a situation where inmates may become aggressive or violent without even realizing their level of escalation of misconduct. Such activity might be their only choice in certain situations where 
they feel satisfied because of the action they have chosen as a manifestation of enjoying freedom. Moreover, individuals entering the prison environment with certain mental health needs can be expected to face maladjustment during their term of incarceration. Previous research suggests that individuals may experience mental health problems as a reaction to their confinement experience (Goodstein, MacKenzie, \& Shotland, 1984; Ruback \& Carr, 1984). This asserts that an individual who enters the prison environment with certain mental health needs can experience maladjustment during the term of incarceration (Toman, 2019).

\section{Prevalence of Mental Health Challenges among Female Inmates}

A large number of existing studies have found a higher prevalence of mental health challenges among female inmates than male inmates (Bloom, \& Covington, 2008; Covington, 2007; Fogel et al., 1992; Fogel, 1993; Fellner, 2006; Green, Miranda, Daroowalla, \& Siddique, 2005; Houser, Belenko \& Brennan, 2012; Lynch, Fritch, \& Heath, 2012). According to Trestman, Ford, Zhang, and Wiesbrock (2007), more women than men (77.0\% vs. $64.9 \%)$ were found to have been diagnosed with a psychiatric disorder. Their study measured anxiety disorders, personality disorders, and functional deficiency, where $56 \%$ of women inmates met the criteria for psychological disorders, and $41.8 \%$ of the female respondents met the criteria for post-traumatic stress disorder (PTSD). Similarly, Dehart, Lynch, Belknap, Brailsford, and Green (2014) found a higher rate of mental health disorders among female inmates. Almost half of the sample had lifetime symptomatic criteria for a severe mental health disorder and PTSD, but substance use disorders were found to be the most prevalent ( $85 \%)$. For example, "inmates who have been abused may be more likely to experience feelings of learned helplessness because of their exposure to situations in which there are no consistent response-outcome contingencies" (Steiner \& Wooldredge, 2009, p.440). In fact, depression, substance dependence, and PTSD are 
found to be the most common mental disorders observed among female inmates (Bloom \& Covington, 2008). In Abram, Teplin, and McClelland's (2003) study, among 1,272 female inmates, $72 \%$ of the female inmates were found to have a severe psychiatric condition including schizophrenia or major disorder and a corresponding substance use disorder. Thus, underlying mental health problems can provide an indication of helplessness to cope with the prison environment, which needs to be addressed.

\section{Prison Environment and Lack of Available Resources}

Due to the rising number of mental health problems among female inmates, adjustment to prison life can become critical for their incarceration period. Generally, people suffering from mental health problems can be found to be more violent toward other inmates, prison staff, as well as toward themselves (Baskin, Sommers, \& Steadman, 1991). Additionally, the prison environment can be hard on an inmates' mental health, with issues like violence, overpopulation, lack of personal privacy, lack of activities, and exercises, seclusion from society along with financial insecurity after prison life. According to Fellner (2006: 394), "apart from the mental health services that may or may not be provided, prisons typically treat prisoners with mental illness identically to all other inmates. There are no special allowances. Officials confine them in the same facilities, expect them to follow the same routines, and require them to comply with the same rules.”

Similarly, Martin and Hesselbrock's (2001) study found that women who have experienced the highest degree of harmful home environments including maltreatment, lack of family supports, are the most likely to suffer from mental health problems. The study asserted that women in a prison environment with the greatest mental health needs experienced the greatest levels of violence, received fewer social supports, and exhibited a greater risk for violent 
behavior. For example, Owen's (1998) study showed that for many female inmates, reuniting with children turns out to be the most important goal, which acts as an informal social control during their prison time.

In one study, Lynch (2017) asserted that there is great difficulty in accessing resources for women who are in need mental of health support. The participants' mental health did not change significantly between the incarceration period and post-release assessment. Indeed, women's PTSD symptoms while incarcerated were found to be identical to post release levels; likewise, depression symptoms while incarcerated were not significantly different from postrelease levels. Lynch (2017) found a close relationship between mental health and previous trauma exposure, violent history of abuse, the difficulty of finding resources or the right personnel with whom to talk, and a history of drug usage. The ultimate impact of these problems gets more critical for inmates whose cognitive and emotional resources have already been exhausted by various mental health challenges such as schizophrenia, bipolar syndrome, PTSD, major depression, and other serious mental disorders (Fellner, 2006). Thus, entering prison life with certain mental health needs can become complex and may require more gender-based programs to assist for easier adjustment to prison life.

\section{Coping Strategies for Inmates with Mental Health Problems}

Coping strategies were found to be interconnected with an individual's psychological adjustment in response to various stressors (Negy, Woods \& Carlson 1997; Warren et al., 2004). According to Jiang and Winfree (2006), an inmate's previous experience can substantially influence adjustment in prison life. For instance, the prison experience can be more complex and painful for female inmates. Because of incarceration, female inmates have to go through separation from their family and loved ones, especially their children (Jones, 1993; Owen, 1998; 
Pollock, 2002; Ward \& Kassebaum, 1965). MacKenzie, Robinson, and Campbell's (1989) study examined the adjustment patterns among female inmates and found that these are determined by the length of sentencing and current time served. Newer Inmates reported encountering fewer problems with their environment. At the same time, to feel safer, they establish a relationship to form various groups known as “play families” (Owen, 1998, p.08). Owen's (1998) study revealed that during the incarceration time, reuniting with children becomes an essential goal for female inmates, which helps them to cope with prison. The finding from the literature provides a clear interpretation of family-oriented coping strategies among female inmates. While establishing relationships among other female inmates, the more support they receive, the lower the rate of rule infractions. Felson and colleagues (2012) argued that persons under high stress fail to perform appropriate interaction rituals as expected by others and may behave in unusual or annoying ways that may instigate an attack. Thus, while going through mental health challenges, obeying prison rules can become more difficult for female inmates.

Most of the prior literature have shown differences in adjustment patterns between males and females, which impacts overall prison rule infractions (Jiang \& Winfree, 2006; Marcum, Hilinski-Rosick, \& Freiburger, 2014; Negy, Woods, \& Carlson, 1997;). The literature indicates that female and male inmates use different coping mechanisms for adjusting to prison life, since they experience different events throughout life. According to Coelho, Hamburg, and Adam (1974) coping is significantly different between males and females. As a result, their in-prison values and behaviors also show a different pattern. Hence, females are more inclined to seek out friends for support, which can be termed as tend and befriend reaction to stressful life circumstances (Hart, 1995; Stroud, Salovey, \& Epel, 2002; Teasdale, Silver, \& Monahan, 2006; 
Taylor et al., 2000). Lack of forming any interpersonal bonds can increase the possibility to engage in misconduct behaviors (Marcum, Hilinski-Rosick, \& Freiburger, 2014).

\section{Prevalence of Rule Infractions among Female Inmates}

A considerable body of literature investigates rule infractions among female inmates who have a mental health problems (Celinska, \& Sung, 2014; Fellner, 2006; Felson, Silver, \& Remster, 2012; Jiang, Fisher-Giorlando, \& Mo, 2005; Negy, Woods, \& Carlson,1997; Steiner, \& Wooldredge, 2009; Tewksbury, Connor, \& Denney, 2014). Mccorkle's (1995) study found that women inmates have a higher likelihood than their male counterparts to have taken prescribed medication for emotional or mental health problems (34.0\% Vs. $20.3 \%)$. The study included a sample of 13,711 inmates (9,075 males and 2,537 females). Mccorkle's study also found that female inmates currently on medication have an annual infractions rate (measured in Chi squares) twice that of female inmates without any mental health problems (2.6 vs. 1.3).

\section{Stress, Mental Illness, and Role of Social Support Moderators for Coping}

According to Felson (1992) and Silver (2002), stress, failure to observe interpersonal interaction formalities, and conflicted social relationships can promote violent behavior against individuals with mental health symptoms. This implies the notion that inmates who are better able to cope with stress in prison can better protect themselves from getting into trouble in prison. In contrast, inmates who are already dealing with mental health symptoms or stress are challenged with subsequent stressful events with which they find it difficult to cope and this results in rule infractions as coping resources become exhausted and individuals turn to rule violation. 


\section{Role of stress model}

Pearlin and colleagues (1981) stress process theory describes the connection between "sources of stress" (eventful experiences and life strains), "mediating resources" (coping and social support), and "manifestation of stress" or outcomes (pp. 338-341). Therefore, the stress model asserts that throughout an individual's life, stress can be triggered, and at this point, individual's look for coping mechanisms where the desired level of social supports can moderate the outcomes. To emphasize the role of moderator, Pearlin and colleagues, (1981: 341) mentioned, "to Individuals, faced with an array of problems and hardships as they move through the life course, do not choose between coping and supports, but use both to avoid, eliminate, or reduce distress." For example, complicated lifestyle challenges, identity crisis along with mental health needs can easily trigger stress among female inmates.

\section{Role of social support moderators}

Since moderators can condition any strong association between two variables (Bennet, 2000), social support moderators have found to be highly influential to condition between mental illness (stress) and rule violating behavior (crime) (Broidy, 2001). Although based on strain theory, mental health problems can be identified as the direct cause for rule infractions, while in the presence of social support moderators, this association may be weakened.

If proper coping strategies or social supports becomes available, then the stress manifestation phase will have fewer negative outcomes, resulting in reduced rule infractions. Whereas, with negative or unavailable resources, female inmates will have negative or aggressive manifestations to stress with more rule infractions. Consistent with the stress model (Pearlin et al., 1981), Silver and Teasdale (2005) also suggested a model that indicates how mental disorder leads to stressful life events and weakened social support, which influences the 
likelihood of violence. It follows that such violence can find its way to rule infractions in the prison setting. By assuring the availability of social support resources or moderators, better coping strategies will become possible among inmates with mental health problems. As a result, social support moderators would be able to intervene to reduce the direct impact of mental health problems on rule infractions.

\section{Social Support and Rule Infractions among Female Inmates with Mental Illness}

Studies show that social supports help inmates to meet their personal needs or place themselves in a safe and secure position within the inmate society (Jiang \& Winfree, 2006; Kawachi \& Berkman, 2001; Lin, 1986). The perceived availability of social support in the face of a stressful event may lead to a more benign appraisal of the situation, thereby preventing a cascade of ensuing negative emotional and behavioral responses (Thoits, 1986). According to Lin (1986), "social support can be defined as the perceived or actual instrumental and/or expressive provisions supplied by the community, social networks, and confiding partners" (p.18). From Lin's definition, social support can be classified into two categories: instrumental and expressive. "The instrumental dimension involves the use of the relationship as a means to a goal, such as seeking a job, getting a loan, or finding someone to babysit" (Lin, 1986, p. 20). Thus, instrumental support can involve material or financial assistance and through providing information, suggestions, and advice and guidance for a relationship (Vaux, 1988). The expressive support, "involves the use of the relationship as an end as well as a means. It is the activity of sharing sentiments, ventilating frustrations, reaching an understanding of issues and problems, and affirming one's own as well as the other's worth and dignity" (Lin, 1986, p. 20). Lin's definition illustrates that though support can occur on different social levels, social support 
can be viewed as a synopsis of social networks, communities, and larger ecological units in which individuals are involved. Moreover, it's been emphasized that among available social supports, perceived emotional support is most crucial for an individual's psychological wellbeing (Cohen \& Wills 1985; Turner \& Lloyd 1999). Clone and Dehart (2014) found emotional support as the most frequent and important type of care being received by incarcerated women, followed by " appraisal, instrumental, and informational support" (p.507). Hence, based on Pearlin and colleagues (1981) stress process model it seems reasonable to hypothesize that inmates with mental health problems who have access to social support resources will be less likely to engage in rule infractions.

\section{Social support resources}

Visitation: The deprivation attribute of visitation indicates when inmates receive more visits (including conjugal visitation), they are less inclined to be involved in a rule violation (Borgman, 1985; Jiang \& Winfree, 2006; Hensley, Koscheski, \& Tewksbury, 2002; McShane \& Williams, 1990). For instance, violating prison rules may result in loss of visiting rights. As a result, to maintain visiting privileges, inmates will be more committed to follow prison rules. Female inmates are more inclined than the male inmates to stay connected with their friends and families through the visitation facility in prison. It can be said that the more they will have visitation, the lesser they will be worried about their family. This is consistent with previous studies regarding the effects of social support strategies on institutional behavior (Borgman, 1985; Hensley et al., 2002; Jiang \& Winfree, 2006; McShane \& Williams, 1990). According to Tewksbury and Connor (2012), inmates who have fewer rule violations received more visits than inmates with more rule infractions. From the deprivation standpoint, this makes sense as inmates who receive more visits are less predisposed to become entirely secluded from the outside world. 
Therefore, they are less deprived of social life (e.g.: family support) and are less likely to adopt negative prison adaptations. On the other hand, inmates who receive fewer visits are more likely to feel isolated, and fear of deprivation subsequently makes rule infractions more likely. As a result, the existing literature shows a positive association between visitation and emotional wellbeing which can lead to fewer rule infractions. Additionally, frequency of prison visits has significance in response to rule infractions. According to Siennick, Mears and Bales (2013: 424), "Less variation in individual visits' effects by overall visit frequency could reflect lasting effects of visits on inmates' conventional attachments and commitments." If visits remain the main support system on which an inmate relays to get relief or diversion from prison pain, then irregular visits might not reflect in expected result for reducing rule infractions.

Pollock's (2002: 111) explanation provides a clearer understanding as to why women inmates need more emotional support through the following lines, "visitation rooms in women's prisons are mostly filled with family members (typically mothers and sisters) and children; visitation rooms in men's prisons are usually filled with wives and girlfriends.” This clearly states the need for family support, which is very evident for female inmates. Consistent with Pollock's (2002) study, Martin and Hesselbrock (2001) found that the most common visitors for female inmates were the mothers (45\%), children (42\%) and their male partners or husbands $(30 \%)$. As a result, being surrounded by family and friends, female inmates can experience less stressful life events and easier adjustment into prison life.

Phone calls: As an accessible method of communication, phone calls have been discussed in literature for relieving anxiety and depression among prisoners (Acevedo \& Bakken, 2001; Banauch 1985; Lapoint 1977; Jinag \& Winfree, 2006; Henriquez, 1982; Stanton 1980; Tyner et al., 2014). According to Jiang and Winfree (2006), phone calls were found to have a 
positive impact for lowering rule infractions among both male and female inmates. Without outside connection, inmates were found to display a feeling of hopelessness and rage (Tyner et al., 2014). Also, to cope with prison life, phone calls with children were found to be helpful for imprisoned mothers (Acevedo \& Bakken, 2001). Thus, because of the complexities of visitation, including cost and time barrier, phone calls are another way for staying connected with family and friends in consideration with prison life adjustment for both male and female inmates.

In-prison program: Prison programs are found to have a positive impact on prison adjustment and reduced rule infractions (Flanagan, 1983; Frey \& Delaney, 1996; Jiang \& Winfree, 2006; Ryan \& McCabe, 1994). According to Frey and Delaney, (1996, p.81), "correctional recreation tends to focus on the role of leisure in raising inmate morale, boredom relief, displaced aggression, and physical fitness as a defense against potential interpersonal violence." Various in-prison activities can improve the deprivation feeling of an inmate by helping them to get involved in groups. Thus, a feeling of social connectedness can be established, which could be helpful to cope with the pains of imprisonment. Overall, access to recreational programs can be provided to inmates to boost positive behavior (e.g.: amenities for physical exercise), whereas such facilities can be canceled in an attempt to control aggressive behavior among inmates (Braxton-Mintz, 2009).

\section{Social Support and Its Impact on Mental Health Problems}

Social support has been found to be helpful for female inmates (Mancini et al., 2016; Pollock, 2002), since females experience life events differently than males (Browne, Miller, \& Maguin, 1999; Pollock, 2002; ; Wright, Salisbury, \& Voorhis, 2007). Social support helps to buffer the effects of stress and helps to prevent any negative outcomes such as providing a sense of "safety and security" within prison community and (Jiang \& Winfree, 2006) easing "pains of 
imprisonment" (Sykes, 1958) by strengthening inmates family bonding (Jiang, Fisher-Giorlando, $\&$ Mo, 2005). Also, interpersonal relations have found to have stronger influences on female inmates than male inmates (Zingraff, 1980).

Though social support can mitigate the effects of stress, it can also act to prevent stresses from emerging (Cullen, 1994). This idea has merits for female inmates and stress processes. For instance, based on Cullen's ideas, social support can reduce the possibility of stress and anxiety by providing visitation or phone call privileges where inmates can feel connected with their family.

\section{Summary}

Recent research indicates that social support was linked to inmate rule infractions at both the individual level and facility level (Jiang \& Winfree, 2006; Jiang, Giorlando, \& Mo, 2005). According to Jiang and his colleagues (2005), inmates who received phone calls from their children were highly unlikely to be involved in any rule infractions compared with inmates without any calls from their children. Hairston (1988) suggested that without access to family, inmates lose hope that they can achieve more in their lives, become more socially isolated and their emotional resources start to shrink. As a result, they may re-offend at higher rates than the previous record. Thus, if inmates suffering from mental health problems do not receive adequate social support, they might manifest stress in a violent or aberrant manner than similar inmates who do receive the needed social supports for coping with prison life.

\section{Current Study}

Though, many studies analyzed rule-breaking behavior among female inmates, very few solely concentrated on mentally ill female inmates. However, they did not widely examine the impact of social support variables on overall rule infractions. Prior studies have typically focused 
on an aggregated sample of male and female inmates (Camp et al., 2003; Cao, Zhao \& Dine 1997; Gover et al., 2008; Huebner, 2003; Harer \& Steffensmeier 1996; Jiang \& FisherGiorlando, 2002; McCorkle, Miethe, \& Drass 1995; Toch, Adams, \& Grant 1989; Wooldredge 1994; Wooldredge, Griffin, \& Pratt 2001). In fact, many researchers discussed the role of social support variables for male and female inmates (Cullen, 1994; Cullen et al., 1999; Hart, 1995; Simon, 1993; Snyder et al., 2002) in prison adjustment and rule infractions ( Acevedo, \& Bakken, 2003; Gendreau, Goggin, \& Law, 1997; Jiang \& Winfree, 2006). Since males are highly over-represented in the above-mentioned studies, it is more likely that the results interpreted from these studies have overrepresented male inmates' experiences. That is, it is possible to miss unique associations that are connected to female inmates only, when examining data that pools male and female inmates.

Therefore, to overcome these limitations, this study disaggregates the samples and explores female inmates separately to investigate the associations between mental health problems and rule infractions in response to social support moderators. By focusing on rule infractions specific to female inmates, this study lessens the risk of male over-representation. Thus, this is one of first studies focused explicitly on female inmates and the impact of social support variable on their rule violating behavior. Therefore, this study provides a more accurate representation between the association of mental health problems of female inmates and prison rule violations. As a result, current research findings would reflect higher chances of generalization and validity. Further, most of the literature reflected on prison visits as a key social support variable on inmates' behavior (Casey-Acevedo \& Bakken, 2001; Casey-Acevedo, Bakken, \& Karle, 2004; Casey-Acevedo \& Bakken, 2002; Christian, 2005; Siennick, Mears, \& 
Bales, 2013). This study tests beyond prison visits and includes telephone calls, mail, prison rewards, involvement in social groups, and other forms of recreational resources.

The current study considers that not all female inmates who experience mental health problems respond with rule infractions. The stress process model identified earlier theorizes that the effects of stress on negative outcomes may be buffered by social support resources. Here, the goal is to examine the impact of social support moderators of the association between mental health problems and rule infractions among female inmates. The current study hypothesizes the followings;

H1: Mental health problems increase rule infractions among female inmates.

H2: Social support variables reduce rule infractions among female inmates.

H3: The association between mental health problems and rule infractions will be decreased in the presence of social supports.

In order to examine these hypotheses, the study uses one of the largest nationally representative datasets of 2,930 female inmates from 357 state prisons - the 2004 survey of inmates in state and federal correctional facilities (SISFCF). 


\section{CHAPTER III: METHODOLOGY}

This chapter covers the methods and techniques that the researcher employed to conduct the study. The researcher here discusses the data, sample, and measurement of the variables. The research used a quantitative survey methodology and multivariate logistic regression analysis to test the conditional effects (moderation) hypothesis.

\section{Data}

The data for this study were provided by the 2004 Survey of Inmates in State Correctional Facilities, in which a total sample of nearly 14,500 state inmates were selected from 1,585 state prisons (United States Bureau of Justice Statistics, 2004). This is the largest available sample on state inmates in the United States. The survey included data on current crime, personal and incidence characteristics, criminal history, drug and alcohol abuse, medical details, use of gun, and prison activities and programs. For obtaining the data, the researcher here used secondary data from the Survey of Inmates in State Correctional Facilities (United States Bureau of Justice Statistics, 2004) which were self-reported. This secondary data sets are publicly accessible and downloaded from the Bureau of Justice (BJS) website, where data sets are available from the Inter-University Consortium for Political and Social Research (ICPSR) website.

\section{Sample}

The sampling used the Bureau of Justice report 2000 Census of State and Federal Correctional Facilities counted on June 30, 2000 (United States Bureau of Justice Statistics, 2004). Female facility frames (sampling frame with female prisoners) were selected with three hundred and fifty-seven state prisons, where 148 facilities included female inmates only, and 209 
facilities included both male and female inmates. Among these facilities, 65 female facilities were selected based on sampling interval criteria. To obtain a nationally representative sample of inmates in state correctional facilities within the United States, the sampling procedure included two phases. The first phase involved sampling a random subset of correctional facilities from all facilities selected through the 2000 Census of State Correctional Facilities. The second phase involved sampling of individuals imprisoned within the sampled facilities. The sampling stages were determined through the original data collector's explanation (United States Bureau of Justice Statistics, 2004).

\section{First Stage of Sampling}

At first, the seven largest female state prisons were selected based on certainty and selfrepresenting (SR) criteria. To meet certainty criteria, selected prisons were categorized based on representation of specific estimated inmate population, where The United States Bureau of Justice Statistics staff included all female correctional institutions with populations larger than 1,808 . The prison population divided by the national inmate sampling interval was larger than 75 (United States Bureau of Justice Statistics, 2004, p.07). For self-representing criteria, prisons with more than 750 female inmates and with the presence of medical, dental and geriatric conditions were identified as SR facilities. After including the 7 largest SR facilities, the remaining facilities were defined as non-self-representing (NSR).

From non-self-representing (NSR) facilities, the rest of the 350 prisons were sampled based on strata. Prisons were classified into eight strata selected by the census regions. The regions included; Texas, Midwest, Florida, South except Florida and Texas, New York, California, West except California, Northeast except New York. The number of NSR facilities to be sampled within the stratum was determined prior to selecting the sample in each stratum. 
NSR facilities were divided by the number of male or female prisoners within the stratum by the total number of populations including male or female prisoners in all NSR facilities.

For example, if 200 female NSR prisons were to be selected for a sample, and stratum A included 30,000 female inmates from 700,000 total females in all NSR prisons, the total number of prisons selected from stratum A would be $(30,000 / 700,000) * 200=8.6$. Therefore, 9 NSR

prisons would be selected from stratum A. The computed sampling interval for stratum A would be $30,000 / 9=3,333$. Using this data followed by a random sampling, any number between zero and the sampling interval was randomly selected. As a result, 58 NSR facilities were selected systematically with probability proportional to size resulting in a total sample of 65 female prisons (58 NSR plus $7 \mathrm{SR}$ ).

\section{Second Stage of Sampling}

During the second phase of sampling, inmates from the 65 sampled facilities were selected to participate in the study. A list of all inmates housed at the facility was obtained from the prison, and a number was assigned to each inmate on the list. Using a randomly selected starting point and a predetermined skip interval, prisoners were selected randomly from the list. Among the 3,054 selected female inmates, 2,930 agreed to participate, with a non-response rate of $4.1 \%$.

\section{Confidentiality}

The data collection for the survey occurred between October 2003 and May 2004. All inmates were informed verbally and in writing before the interview that the participation was voluntary. Also, inmates were informed that all information provided by them would be held in confidence. Participants were informed that the survey was conducted only for statistical 
purposes and that every individual who participated would not be identified. This current study did not require a full Institutional Review Board (IRB) review, since the study analyzed publicly available secondary data. The original study 2004 Survey of Inmates in State Correctional Facilities (SISCF) has already adhered to the standards for ethical research practices as the study was conducted for the Bureau of Justice Statistics (BJS) by the Bureau of the Census.

\section{Measures}

This section covers variables for analysis for this study. The researcher here discusses dependent variables which includes major rule infractions, minor rule infractions, substancerelated rule infractions; independent variables (mental Illness), control variables and social support variables. Also, this section includes a table which contains the all variables along with their codes for the logistics regression analysis. The table also contains Case characteristics for group variables.

Table 1. Variables.

\begin{tabular}{|c|c|c|}
\hline Variables & Coding & \\
\hline Major rule infractions & $1=$ yes & $0=$ no \\
\hline Minor rule infractions & $1=$ yes & $0=$ no \\
\hline Substance related rule infractions & $1=$ yes & $0=$ no \\
\hline \multicolumn{3}{|l|}{$\underline{\text { Case characteristics }}$} \\
\hline Drug violation & $1=$ yes & $0=$ no \\
\hline Alcohol violation & $1=$ yes & $0=$ no \\
\hline Possession of a weapon & $1=$ yes & $0=$ no \\
\hline Stolen property & $1=$ yes & $0=$ no \\
\hline Possession of some other unauthorized item, substance, or contraband & $1=$ yes & $0=$ no \\
\hline Verbal assault on staff & $1=$ yes & $0=$ no \\
\hline Physical assault on staff & $1=$ yes & $0=$ no \\
\hline
\end{tabular}

(Table Continues) 
Table 1. (Continues)

\begin{tabular}{lll}
\hline Variables & Coding \\
\hline Verbal assault on inmate & $1=$ yes & $0=$ no \\
Physical assault on inmate & $1=$ yes & $0=$ no \\
Escape or attempted escape & $1=$ yes & $0=$ no \\
Being out of place & $1=$ yes & $0=$ no \\
Disobeying orders & $1=$ yes & $0=$ no \\
Other major violations including work slowdowns, food strikes, setting fires,, & $1=$ yes & $0=$ no \\
rioting, etc. & & \\
Any minor violations such as use of abusive language, horseplay, failing to & $1=$ yes & $0=$ no \\
follow sanitary regulations, etc. & &
\end{tabular}

\section{Mental Illness and Substance Use}

A depressive disorder

$1=$ yes $0=$ no

Manic-depression, bipolar disorder, or mania

$1=$ yes $\quad 0=$ no

Schizophrenia or another psychotic disorder

$1=$ yes $\quad 0=$ no

Post-traumatic stress disorder

$1=$ yes $0=$ no

Another anxiety disorder, such as a panic disorder

$1=$ yes $0=$ no

A personality disorders

$1=$ yes $0=$ no

Any other mental or emotional condition

$1=$ yes $0=$ no

Drug use (ranges 0-14)

$1=$ yes $0=$ no

\section{Social Support}

Visitation

Mail

Telephone Call

Prison rewards

Availability of resources

$1=$ yes $0=$ no

$1=$ yes $0=$ no

$1=$ yes $0=$ no

$1=$ yes $0=$ no

$1=$ yes $\quad 0=$ no

Involvement in social groups

$1=$ yes $\quad 0=$ no

\section{Demographic characteristics}

Race:

White

Black

All other races

$1=$ yes $\quad 0=$ no

$1=$ yes $0=$ no

$1=$ yes $0=$ no

(Table Continues) 
Table 1. (Continues)

\begin{tabular}{ll}
\hline Variables & Coding \\
\hline$\underline{\text { Education }}$ & \\
General equivalency diploma/ High school & $1=$ yes $0=$ no \\
Marital Status & \\
Married & $1=$ yes $0=$ no \\
Widowed or Divorced or Separated & $1=$ yes $0=$ no \\
Never married & $1=$ yes $0=$ no \\
Children & $1=$ yes $0=$ no \\
Income & In dollars \\
Sentence Length & In Years \\
Age & In Years \\
\hline
\end{tabular}

\section{Dependent Variable: Rule Infractions}

In this study, rule infractions were measured in terms of whether participants were ever found to be guilty of, or written up, or any institutional rule violations. This is consistent with previous studies (Teasdale et al., 2016). Participants were asked "Since your admission, have you been written up for or been found guilty of" for the following: (1) drug violation? (2) alcohol violation? (3) possession of a weapon? (4) stolen property? (5) possession of some other unauthorized item, substance, or contraband? (6) verbal assault on staff? (7) physical assault on staff? (8) verbal assault on inmate? (9) physical assault on inmate? (10) escape or attempted escape? (11) being out of place? (12) disobeying orders? (13) other major violations including work slowdowns, food strikes, setting fires, rioting, etc.? 14) any minor violations such as use of abusive language, horseplay, failing to follow sanitary regulations, etc.? The survey provided response options as yes, or no. For this study, any positive response to the survey questions was coded as yes or 1 and no to all items was coded no or 0 . Also, rule infractions has been divided 
into three categories including major rule infractions, minor rule infractions and substancerelated rule infractions. Major rule infractions included all major or serious rule violations that were asked to the participants. Minor rule infractions included non-violent rule break from the above 14 category and any substance-related rule violations (e.g.: drug or any alcohol).

\section{Independent Variable: Mental Illness}

Mental illness was measured as any mental health problems or symptoms which may hinder the ability to conduct an inmate's regular activity. Mental health problems were based on the self-reported data from the survey question; "Have you ever been told by a mental health professional, such as a psychiatrist or psychologist, that you had" 1) a depressive disorder 2) manic-depression, bipolar disorder, or mania 3) schizophrenia or another psychotic disorder 4) post-traumatic stress disorder 5) another anxiety disorder, such as a panic disorder 6) a personality disorder (such as an antisocial or borderline personality disorder) 7) any other mental or emotional condition. Participants were given yes or no response option. For this study, participants who responded yes to any of these questions were coded as 1 and subjects who responded no to all the questions were coded 0.

\section{Moderating Variable: Social Support}

Social support was measured in terms of any received emotional or tangible support from within prison or from friends and family. The variables include visitations, mail from children, telephone calls from family and friends, involvement in social groups, prison rewards and availability of various resources. For prison rewards, both monetary and nonmonetary rewards have been included. 
Visitation: An in-person visit by friends or family members were measured for the visitation variable. Participants were asked, "In the past month, have you had any visits, not counting visits from lawyers?" "Were you allowed to have any visits?" For these questions, the survey provided response options as yes, or no. For this study, any yes response was coded as 1 and no as 0 . Also, to measure the frequency of visitations, the survey included "And how often have you been personally visited by your child(ren)?” Response options included 1) daily or almost daily 2) at least once a week 3) at least once a month 4) less than once a month, and 5) never. Visits has been recoded as 1 whereas no, never has been recoded as 0 .

Mail: Any letter received from children was measured for mail. Participants were asked, “And how often have you sent or received mail from your child(ren)?” The questionnaire provided options as, 1) daily or almost daily 2) at least once a week 3) at least once a month 4) less than once a month, and 5) never. Receiving mail daily, once a week, once a month and less than once a month has been recoded as 1 whereas no, never has been recoded as 0 .

Telephone call: A phone call received from friends and family was considered a component of emotional support. Participants were asked, "Are you allowed to talk on the telephone with friends and family?" The survey provided response options as yes, or no. For this study, any yes response was coded as 1 and no as 0 . Also, the frequency of telephone calls was asked: "Since your admission to prison on, about how often have you made or received calls from your child(ren)?" with the following response categories : 1) daily or almost daily 2) at least once a week 3) at least once a month 4) less than once a month, and 5) never. Receiving phone calls daily, once a week, once a month and less than once a month has been recoded as 1 whereas no, never has been recoded as 0 . 
Involvement in social groups: Any opportunity that can provide a chance for involvement in social groups was measured for this variable. The participants were asked "Since your admission to prison on have you joined or participated in:” 1) A Bible club or other religious study group (including Muslims)? 2) an ethnic/racial organization (for example, NAACP, African American or Black Culture group, Hispanic Committee, Aztlan, or Lakota)? 3) inmate assistance groups (for example, inmate liaison, advisory, or worker's councils) or inmate counseling groups? 4) other inmate self-help/personal improvement groups, for example, toastmasters, Jaycees, gavel club, veterans club, or parent's awareness groups? the questionnaire provided yes or no response options. For this study, yes responses were coded as 1 and no as 0 .

Prison rewards: Rewards can be both monetary and nonmonetary. Any reward that does not have any monetary value has been measured as non-monetary reward. Whereas monetary reward, considered mainly the monetary value given to the inmates at any points in their prison time. For non-monetary reward the participants were asked, "Other than money, do you receive anything for work, such as time credits or other privileges?" A yes or no response option was provided in the questionnaire.

For monetary rewards, participants were asked "Are you paid money for any of this work?" for the following categories; 1) general janitorial duties (cleaning/orderly/sweeping) (2) grounds or road maintenance (3) food preparation or related duties (kitchen, bakery, butchery, etc.) (4) laundry (5) hospital, infirmary, or other medical services (6) farming/forestry/ranching (7) goods production/industries/contract services (telemarketing, tag shop, print shop, etc.) (8) other services such as library, stockroom, store, office help, recreation, sew shop, barber or beauty shop, etc. (9) maintenance or repair/construction. For both questions, the survey provided yes or no response options. For this study, yes responses were coded as 1 and no as 0. 
Availability of resources: Resources that can provide a sense of attachment to society were measured for this variable. Is there a television available for you to watch in this prison? In the last 24 hours, did you watch any television? Are there any newspapers, magazines or books available to you, either in the library or from other inmates? In the last 24 hours, did you spend any time reading? In the last 24 hours, did you spend any time in other kinds of recreation, for example, arts, crafts, playing cards or other games? The questionnaire provided yes or no response options. For this study, yes responses were coded as 1 and no as 0 .

\section{Control Variables}

Age: Participants were asked, "How old are you?" Age in years is measured as a control variable, since younger individuals may be more prone to rule infractions.

Race: Race was also considered for the purpose of the study. The original questionnaire on race and ethnicity collected data through two questions, "Which of these categories describes your race? Mark all that apply." The question included responses for following six categories; (1) White; (2) Black (3) American Indian or Alaska Native; (4) Asian; (5) Native Hawaiian or other Pacific Islander; (6) All other races.” For the second question, participants also indicated whether they were of Hispanic origin. Additionally, participants who indicated membership in multiple race categories were grouped into this same collective "other" category. The final variable for race used in the present study had three possible values: White, Black or African American, mixed race/all other race.

Education: Education has been measured in terms of a GED or high school diploma. Participants were asked, "Do you have a GED, that is, a high school equivalency certificate?" 
The questionnaire provided yes or no response options. For this study, yes responses were coded as 1 and no as 0 .

Marital Status: In the original study marital status included 5 possible options to respond, 1) married, 2) widowed, 3) divorced 4) separated, and 5) never married. Here, widowed, divorced and separated were grouped together which resulted in three categories for marital status including: 1) married 2) widowed/divorced/separated and 3) never married.

Children: Participants were asked, "Do you have any children, including step- or adopted children?" The survey question provided yes or no response options. For this study, yes responses were coded as 1 and no as 0 .

Income: Income was measured in terms of the amount of money an inmate has made during the month before the arrest. Participants were asked, "Which category on this card represents your personal monthly income from ALL sources for the month before your arrest?" for the following responses: (0) No income (1) \$1 - 199 (2) 200 - 399 (3) 400 - 599 (4) 600 799 (5) 800 - 999 (6) 1,000 - 1,199 (7) 1,200 - 1,499 (8) 1,500 - 1,999 (9) 2,000 - 2,499 (10) 2,500 - 4,999 (11) 5,000 - 7,499 (12) 7,500 or more (D) Don't know.

Sentence length: Sentence length will be measured in years. For maximum sentencing length range was given as 1-99 for years. Flat years has been adjusted for missing values for maximum sentence lengths. If the system found missing value for maximum sentence length, then the flat sentence for that field has been adjusted for maximum sentence lengths.

Drug use: Participants were asked, "Have you ever used 1) heroin? 2) other opiates, for example, Darvon or Percodane without a doctor's prescription or methadone outside a treatment program? 3) methamphetamine such as ice or crank? 4) other amphetamine without a doctor's 
prescription such as speed? 5) Methaqualone such as Quaaludes without a doctor's prescription? 6) barbiturates without a doctor's prescription, such as downers? 7) tranquilizers such as Valium without a doctor's prescription? 8) crack? 9) cocaine other than crack? 10) PCP? 11) Ecstasy? 12) LSD or other hallucinogens? 13) marijuana or hashish? 14) any other drugs that we didn't mention?" Yes, responses were coded as 1 and No responses were coded as 0.

\section{Data Analysis}

To examine the statistical significance of the research hypothesis, the data set was analyzed using a Statistical Package for Social Sciences (SPSS). IBM SPSS 25 version was used to clean and perform primary descriptive analyses. Since the hypotheses included more than one independent variable, multivariate logistic regression analysis was conducted. According to Alexopoulos (2010), logistic regression analysis is best suited to model where the dependent variable is dichotomous. Multivariate logistic regression allows the inclusion of multiple predictor variables (independent variables) predicting one dependent variable. For example: this study tests the effect of social support and mental health problems on female inmate's rule infractions, where rule infractions coded as dichotomous dependent variable. This statistical method allowed this study to (1) assess if there is any correlation between mental health problems and rule violations; (2) examine the positive or negative correlation between social support moderators and rule infractions; and (3) assess whether the correlation between mental illnesses and rule infractions differs given the availability (or absence) of social support moderators. 


\section{Missing Data}

Before assigning dummy variables for data analyses, missing values were assessed first. "Missing values can appear because respondent did not answer all questions in questionnaire, during manual data entry process, incorrect measurement, faulty experiment, some data are censored or anonymous and many others" (Kaiser, 2014, p.42). Skip patterns in the SISCF 2004 questionnaire were studied to determine if missing values were the result of negative responses to the earlier set of questions. Any answer as "DK" or do not know was calculated as system missing data.

The researcher here created a syntax for listwise deletion to clean data for dependent variables. The analyses included only those data that do not have missing values. Since the sample size was large enough the fear of biasness was minimal (Graham, 2009). Following the listwise deletion the original sample size was reduced from 2930 to 1299.

To adjust for multivariate analysis, median and mean imputation has been used following the convention set forth by Malarvizhi, \& Thanamani (2012, P.05). A dichotomous indicator has been created for the categorical variables where missing values were adjusted by mode and zero. And for continuous variable missing values have been adjusted by the mean value. 


\section{CHAPTER IV: RESULTS}

This section includes the results of the current study. This chapter begins with a descriptive analysis of the sample followed by bivariate and multivariate analyses. Finally, to evaluate the research hypotheses, the analysis from the logistic regression model is presented.

\section{Univariate Analysis: Sample Description}

Table 2 describes the sample characteristics of the female inmates. Minor rule infractions (74.7\%) were most frequent among female inmates, followed by substance-related (29.9\%) and major rule infractions (27.3\%). Out of 1299 inmates, almost half of the sample had mental health problems (55\%). On average, a female inmate received almost 5 social supports, on a scale from 0 to 6 . The average age for a female inmate was about 35 . On average, the respondents made an income of 1,000 to 1,199 dollars the month before their arrest. The majority (53\%) of the sample were single/never married. Most of the sample was White (49\%), followed by Black (39.6\%), and all other races (11.4\%). A majority of the sample had children (77.1\%). Almost a third of the sample completed a high school education or its equivalent (29.6\%). The average maximum sentence length was almost ten years. The average number of drugs used in the past 12 months before incarceration was 3.60 .

Table 2. Descriptive Statistics.

\begin{tabular}{lllll}
\hline Variable name & Mean or $\%$ & SD & Min & Max \\
\hline
\end{tabular}

\section{Dependent}

Major rule infractions

Minor rule infractions

Substance-related rule infractions
$27.3 \%$

$74.7 \%$

$29.9 \%$

$\begin{array}{lll}- & 0 & 1 \\ - & 0 & 1 \\ - & 0 & 1\end{array}$

(Table Continues) 
Table 2. (Continues)

\begin{tabular}{|c|c|c|c|c|}
\hline Variable name & Mean or \% & SD & Min & Max \\
\hline \multicolumn{5}{|l|}{ Independent } \\
\hline Mental Illness & $55 \%$ & - & 0 & 1 \\
\hline Social Support & 4.99 & .90 & 2 & 6 \\
\hline \multicolumn{5}{|l|}{ Control } \\
\hline Age & 34.28 & 9.38 & 18 & 74 \\
\hline Income & 4.83 & 3.60 & 0 & 12 \\
\hline \multicolumn{5}{|l|}{ Race: } \\
\hline White & $49 \%$ & - & 0 & 1 \\
\hline Black & $39.6 \%$ & - & 0 & 1 \\
\hline All other Races & $11.4 \%$ & - & 0 & 1 \\
\hline \multicolumn{5}{|l|}{ Marital Status: } \\
\hline Married & $32.7 \%$ & - & 0 & 1 \\
\hline Widowed/Separated/Divorced & $14.2 \%$ & - & 0 & 1 \\
\hline Never married & $53 \%$ & - & 0 & 1 \\
\hline \multicolumn{5}{|l|}{ Education: } \\
\hline GED/HS graduate & $29.6 \%$ & - & 0 & 1 \\
\hline Children & $77.1 \%$ & - & 0 & 1 \\
\hline Drug use & 3.60 & 3.30 & 0 & 13 \\
\hline Sentence length (maximum) & 9.92 & 8.30 & 1 & 99 \\
\hline
\end{tabular}

Note. $\mathrm{n}=1299$; income coded $0=$ none and $12=\$ 7,500$ or more; GED $=$ general equivalency diploma; HS $=$ high school.

\section{Bivariate Analysis: Crosstabs}

As shown in Table 3, inmates who have mental health problems have similar involvement in major rule infractions (28.1\%) compared to that (26.2\%) of inmates who do not have mental health problems. The analysis shows a significant relationship between marital status and major rule infractions. Inmates who were never married (34.7\%) have higher rates of major rule infractions, followed by married (21.1\%) and Widowed/Separated/Divorced (17.9\%). 
Inmates who were White $(22.3 \%)$ have significantly lower rates of major rule infractions than nonwhites (32.0\%). On the other hand, Inmates who were Black (33.1\%) have significantly higher rates of major rule infractions than inmates who were not Black (23.4\%). Similarly, inmates in all other races $(28.4 \%)$ category showed somewhat higher rates of major rule infractions than inmates who responded no to other race categories $(27.1 \%)$, but this was not statistically significant. Moreover, inmates with children (35.4\%) showed significantly higher rates of major rule infractions than inmates who do not have children (24.9\%).

Table 3. Crosstabs: Major Rule Infractions and Independent Variables.

\begin{tabular}{|c|c|c|c|c|}
\hline \multirow[t]{2}{*}{ Variables } & & \multicolumn{3}{|c|}{ Major rule infractions } \\
\hline & & No & Yes & Chi-Square \\
\hline \multirow[t]{4}{*}{ Mental Illness } & No & 431 & 153 & .59 \\
\hline & $\%$ & $73.8 \%$ & $26.2 \%$ & \\
\hline & Yes & 514 & 201 & \\
\hline & $\%$ & $71.9 \%$ & $28.1 \%$ & \\
\hline \multirow[t]{5}{*}{ White } & No & 450 & 212 & \\
\hline & $\%$ & $68 \%$ & $32 \%$ & $15.51 * * *$ \\
\hline & Yes & 495 & 142 & \\
\hline & $\%$ & $77.7 \%$ & $22.3 \%$ & \\
\hline & No & 601 & 184 & \\
\hline \multirow[t]{3}{*}{ Black } & $\%$ & $76.6 \%$ & $23.4 \%$ & $14.54 * * *$ \\
\hline & Yes & 344 & 170 & \\
\hline & $\%$ & $66.9 \%$ & $33.1 \%$ & \\
\hline \multirow[t]{4}{*}{ All other races } & No & 839 & 312 & \\
\hline & $\%$ & $72.9 \%$ & $27.1 \%$ & .11 \\
\hline & Yes & 106 & 42 & \\
\hline & $\%$ & $71.6 \%$ & $28.4 \%$ & \\
\hline \multicolumn{5}{|l|}{ Marital Status: } \\
\hline & No & 799 & 315 & $4.14^{*}$ \\
\hline \multirow[t]{3}{*}{ Married } & $\%$ & $71.7 \%$ & $28.3 \%$ & \\
\hline & Yes & 146 & 39 & \\
\hline & $\%$ & $78.9 \%$ & $21.1 \%$ & (Table continues) \\
\hline
\end{tabular}


Table 3. (Continues)

\begin{tabular}{|c|c|c|c|c|}
\hline \multirow[t]{2}{*}{ Variables } & & \multicolumn{2}{|c|}{ Major rule infractions } & \multirow[t]{2}{*}{ Chi Square } \\
\hline & & No & Yes & \\
\hline \multirow[t]{4}{*}{ Widowed/Separated/Divorced } & No & 596 & 278 & \\
\hline & $\%$ & $68.2 \%$ & $31.8 \%$ & $27.97 * * *$ \\
\hline & Yes & 349 & & \\
\hline & $\%$ & $82.1 \%$ & $17.9 \%$ & \\
\hline \multirow[t]{4}{*}{ Never married } & No & 495 & 115 & $40.92 * * *$ \\
\hline & $\%$ & $81.1 \%$ & $18.9 \%$ & \\
\hline & Yes & 450 & 239 & \\
\hline & $\%$ & $65.3 \%$ & $34.7 \%$ & \\
\hline \multicolumn{5}{|l|}{ Education: } \\
\hline \multirow[t]{4}{*}{ GED/HS graduate } & No & 668 & 246 & \\
\hline & $\%$ & $73.1 \%$ & $26.9 \%$ & .18 \\
\hline & Yes & 277 & 108 & \\
\hline & $\%$ & $71.9 \%$ & $28.1 \%$ & \\
\hline \multirow[t]{4}{*}{ Children } & No & 192 & 105 & \\
\hline & $\%$ & $64.6 \%$ & $35.4 \%$ & $12.75 * * *$ \\
\hline & Yes & 753 & 249 & \\
\hline & $\%$ & $75.1 \%$ & $24.9 \%$ & \\
\hline
\end{tabular}

Note: $\mathrm{GED}=$ general equivalency diploma; HS $=$ high school, $* \mathrm{p}<.05,{ }^{* *} \mathrm{p}<.01, * * * \mathrm{P}<.001$

As shown in Table 4, inmates with mental health problems have significantly higher rates of minor rule infractions (78\%) than inmates who do not have mental health problems $(70.5 \%)$. Inmates who were White (72.8\%) have similar rates of minor rule infractions compared with inmates who were nonwhites (74.4\%). However, inmates who were Black (78\%) have significantly higher rates of minor rule infractions than inmates who were not Black (72.5\%). Moreover, Inmates who were never married (77.6\%) have a significantly higher rate of minor rule infractions than widowed/separated/divorced groups (72.5\%). Inmates with education (76.1\%) showed similar rates of minor rule infractions compared to inmates with no education (74.1\%). Inmates with children (73.2\%) showed significantly less involvement in minor rule infractions than inmates who do not have children (79.8\%). 
Table 4. Crosstabs: Minor Rule Infractions and Independent Variables.

\begin{tabular}{|c|c|c|c|c|}
\hline \multirow[t]{2}{*}{ Variables } & & \multicolumn{2}{|c|}{ Minor rule infractions } & \multirow[b]{2}{*}{ Chi-Square } \\
\hline & & No & Yes & \\
\hline \multirow{4}{*}{ Mental Illness } & No & 172 & 412 & $9.54 * *$ \\
\hline & $\%$ & $29.5 \%$ & $70.5 \%$ & \\
\hline & Yes & 157 & 558 & \\
\hline & $\%$ & $22 \%$ & $78 \%$ & \\
\hline \multirow[t]{5}{*}{ White } & No & 156 & 506 & \\
\hline & $\%$ & $23.6 \%$ & $76.4 \%$ & 2.22 \\
\hline & Yes & 173 & 464 & \\
\hline & $\%$ & $27.2 \%$ & $72.8 \%$ & \\
\hline & No & 216 & 569 & \\
\hline \multirow[t]{3}{*}{ Black } & $\%$ & $27.5 \%$ & $72.5 \%$ & \\
\hline & Yes & 113 & 401 & $5.02 *$ \\
\hline & $\%$ & $22.0 \%$ & $78.0 \%$ & \\
\hline \multirow[t]{4}{*}{ All other races } & No & 286 & 865 & \\
\hline & $\%$ & $24.8 \%$ & $75.2 \%$ & 1.23 \\
\hline & Yes & 43 & 105 & \\
\hline & $\%$ & $29.1 \%$ & $70.9 \%$ & \\
\hline Marital Status: & No & 271 & 843 & \\
\hline \multirow[t]{3}{*}{ Married } & $\%$ & $24.3 \%$ & $75.7 \%$ & $4.14^{*}$ \\
\hline & Yes & & 127 & \\
\hline & $\%$ & $31.4 \%$ & $68.6 \%$ & \\
\hline \multirow[t]{4}{*}{ Widowed/Separated/Divorced } & No & 212 & 662 & \\
\hline & $\%$ & $24.3 \%$ & $75.7 \%$ & 1.62 \\
\hline & Yes & 117 & 308 & \\
\hline & $\%$ & $27.5 \%$ & $72.5 \%$ & \\
\hline
\end{tabular}


Table 4. (Continues)

\begin{tabular}{|c|c|c|c|c|}
\hline \multirow[t]{2}{*}{ Variables } & & \multicolumn{2}{|c|}{ Minor rule infractions } & \multirow[t]{2}{*}{ Chi-Square } \\
\hline & & No & Yes & \\
\hline Never married & $\begin{array}{l}\text { No } \\
\% \\
\text { Yes } \\
\%\end{array}$ & $\begin{array}{l}175 \\
28.7 \% \\
154 \\
22.4 \%\end{array}$ & $\begin{array}{l}435 \\
71.3 \% \\
535 \\
77.6 \%\end{array}$ & $6.87 * *$ \\
\hline Education & & & & \\
\hline GED/HS graduate & $\begin{array}{l}\text { No } \\
\% \\
\text { Yes } \\
\%\end{array}$ & $\begin{array}{l}237 \\
25.9 \% \\
92 \\
23.9 \%\end{array}$ & $\begin{array}{l}677 \\
74.1 \% \\
293 \\
76.1 \%\end{array}$ & .59 \\
\hline Children & $\begin{array}{l}\text { No } \\
\% \\
\text { Yes } \\
\%\end{array}$ & $\begin{array}{l}60 \\
20.2 \% \\
269 \\
26.8 \%\end{array}$ & $\begin{array}{l}237 \\
79.8 \% \\
733 \\
73.2 \%\end{array}$ & $5.35^{*}$ \\
\hline
\end{tabular}

Results presented in table 5 demonstrate that inmates who have mental illness have similar rates of involvement in substance-related rule infractions (31\%) compared to the rate (28.4\%) of substance-related rule infractions for inmates who do not have mental illness.

Findings from the race category were opposite to the findings from table 3 and table 4 . Inmates who were White (34.9\%) have significantly higher substance-related rule infractions rate than nonwhites (25.1\%). Black inmates (23.2\%) have significantly lower substance-related rule infractions rate than inmates who were not Black (34.3\%). Married inmates showed a similar rate of involvement in substance-related rule infractions rate of $24.9 \%$ compared with Widowed/Separated/Divorced (30.6\%) and never married individuals (30.8\%). Inmates with general equivalency diploma or high school completion showed significantly lower rates of involvement in substance-related rule infractions (36.6\%) than inmates who do not have an 
education $(27 \%)$. Also, inmates with children showed a substance-related rule infractions rate of $28.8 \%$ which is similar to the substance-related rule infractions rate of inmates without children $(33.3 \%)$.

Table 5. Crosstabs: Substance-Related Rule Infractions and Independent Variables.

\begin{tabular}{|c|c|c|c|c|}
\hline \multirow[t]{2}{*}{ Variables } & & \multicolumn{3}{|c|}{ Substance-related rule infractions } \\
\hline & & No & Yes & Chi-Square \\
\hline \multirow[t]{4}{*}{ Mental Illness } & No & 418 & 166 & 1.06 \\
\hline & $\%$ & $71.6 \%$ & $28.4 \%$ & \\
\hline & Yes & 493 & 222 & \\
\hline & $\%$ & $69 \%$ & $31 \%$ & \\
\hline \multirow[t]{5}{*}{ White } & No & 496 & 166 & \\
\hline & $\%$ & $74.9 \%$ & $25.1 \%$ & $14.81 * * *$ \\
\hline & Yes & 415 & 222 & \\
\hline & $\%$ & $65.1 \%$ & $34.9 \%$ & \\
\hline & No & 516 & 269 & \\
\hline \multirow[t]{3}{*}{ Black } & $\%$ & $65.7 \%$ & $34.3 \%$ & $18.32 * * *$ \\
\hline & Yes & 395 & 119 & \\
\hline & $\%$ & $76.8 \%$ & $23.2 \%$ & \\
\hline \multirow[t]{4}{*}{ All other races } & No & 810 & 341 & .28 \\
\hline & $\%$ & $70.4 \%$ & $29.6 \%$ & \\
\hline & Yes & 101 & 47 & \\
\hline & $\%$ & $68.2 \%$ & $31.8 \%$ & \\
\hline Marital Status: & No & 772 & 342 & \\
\hline \multirow[t]{3}{*}{ Married } & $\%$ & $69.3 \%$ & $30.7 \%$ & 2.58 \\
\hline & Yes & 139 & 46 & \\
\hline & $\%$ & $75.1 \%$ & $24.9 \%$ & \\
\hline \multirow[t]{4}{*}{ Widowed/Separated/Divorced } & No & 616 & 258 & \\
\hline & $\%$ & $70.5 \%$ & $29.5 \%$ & .16 \\
\hline & Yes & 295 & 130 & \\
\hline & $\%$ & $69.4 \%$ & $30.6 \%$ & \\
\hline \multirow[t]{4}{*}{ Never married } & No & 434 & 176 & \\
\hline & $\%$ & $71.1 \%$ & $28.9 \%$ & .57 \\
\hline & Yes & 477 & 212 & \\
\hline & $\%$ & $69.2 \%$ & $30.8 \%$ & \\
\hline
\end{tabular}


Table 5. (Continues)

\begin{tabular}{|c|c|c|c|c|}
\hline \multirow[t]{2}{*}{ Variables } & & \multicolumn{2}{|c|}{$\begin{array}{l}\text { Substance-related rule } \\
\text { infractions }\end{array}$} & \multirow[t]{2}{*}{ Chi-Square } \\
\hline & & No & Yes & \\
\hline \multicolumn{5}{|l|}{ Education } \\
\hline \multirow[t]{4}{*}{ GED/HS graduate } & No & 667 & 247 & \\
\hline & $\%$ & $73.0 \%$ & $27.0 \%$ & $11.92 * * *$ \\
\hline & Yes & 244 & 141 & \\
\hline & $\%$ & $63.4 \%$ & $36.6 \%$ & \\
\hline \multirow[t]{4}{*}{ Children } & No & 198 & 99 & \\
\hline & $\%$ & $66.7 \%$ & $33.3 \%$ & 2.21 \\
\hline & Yes & 713 & 289 & \\
\hline & $\%$ & $71.2 \%$ & $28.8 \%$ & \\
\hline
\end{tabular}

Bivariate Analysis: t-tests

Table 6 compares mean differences of independent continuous variables for major rule infractions. Average age was found to be significantly different between inmates who have major rule infractions (32.16) compared with inmates who have no major rule infractions (35.08).

There were no other significant differences between those with and without a major rule infraction on the other continuous independent variables.

Table: 6. Independent Sample T-Test (Major Rule Infractions and Independent Variables).

\begin{tabular}{llll}
\hline Variables & \multicolumn{2}{c}{$\begin{array}{c}\text { Major rule infractions } \\
\text { Y }\end{array}$} & \\
& Yes & No & $\mathrm{t}$ \\
\hline Social Support & 4.97 & 5.00 & .38 \\
Age & 32.16 & 35.08 & $5.05^{* * *}$ \\
Monthly income & 4.84 & 4.82 & .09 \\
Drug use & 3.45 & 3.66 & 1.0 \\
Sentence length in years & 10.23 & 9.81 & .82 \\
(Maximum) & & & \\
\hline
\end{tabular}


Note: $* \mathrm{p}<.05 * * \mathrm{p}<.01, * * * \mathrm{P}<.001$

Table 7 compares mean differences of independent continuous variables for minor rule infractions. Age was found to be significantly different between inmates who have minor rule infractions (33.58) compared with inmates who have no minor rule infractions (36.36). There were no other significant differences between inmates with and without minor rule infractions on the other independent variables included in Table 7.

Table 7. Independent Sample T-Test (Minor Rule Infractions and Independent Variables).

\begin{tabular}{llcl}
\hline Variables & \multicolumn{3}{c}{$\begin{array}{c}\text { Minor rule infractions } \\
\text { M }\end{array}$} \\
& Yes & No & $\mathrm{t}$ \\
\hline Social Support & 4.98 & 5.02 & .80 \\
Age & 33.58 & 36.36 & $4.67^{* * *}$ \\
Monthly income & 4.84 & 4.79 & .23 \\
Drug use & 3.61 & 3.58 & .11 \\
$\begin{array}{l}\text { Sentence length } \\
\text { (Maximum) }\end{array}$ & 10.01 & 9.66 & .66 \\
\hline
\end{tabular}

Note: $* \mathrm{p}<.05 * * \mathrm{p}<.01, * * * \mathrm{P}<.001$

Table 8 compares mean differences of independent continuous variables for substancerelated rule infractions. The average social support was 5.1 for individuals with a substancerelated rule infraction and 4.94 for individuals without substance-related rule infractions. This indicates significantly more social support amongst those with substance-related rule infractions. Finally, those with longer sentences were more likely to have a substance-related rule infraction than those with shorter sentences. 
Table 8. Independent Sample T-Test (Substance-Related Rule Infractions and Independent Variables)

\begin{tabular}{lccc}
\hline Variables & \multicolumn{3}{c}{ Substance- related rule infractions } \\
& Yes & M No & $\mathrm{t}$ \\
\hline Social Support & 5.10 & 4.94 & $2.83^{* *}$ \\
Age & 33.97 & 34.42 & .78 \\
Monthly income & 4.98 & 4.77 & .97 \\
Drug use & 3.81 & 3.51 & 1.52 \\
$\begin{array}{l}\text { Sentence length } \\
\text { (Maximum) }\end{array}$ & 11.32 & 9.32 & $4.00^{* * *}$ \\
& & & \\
\hline
\end{tabular}

Note: $* \mathrm{p}<.05 * * \mathrm{p}<.01, * * * \mathrm{P}<.001$

\section{Multivariate Analysis: Logistic Regression Model}

Table-9 shows the impact of mental illness and social support variables for major, minor and substance-related rule infractions. Increasing mental health problems, increased the odds of minor rule infractions for female inmates by 1.58 times. Likewise, an increase in social support increased the odds of substance-related rule infractions by 1.19 times. Compared to the never married group, being married and widowed/separated/divorced, significantly decreased the odds for major rule infractions. Compared to the White group, being Black increased the odds of major and minor rule infractions $(\mathrm{OR}=1.522$ and $\mathrm{OR}=1.417)$, but decreased the odds of substance-related rule infractions. Being educated increased the odds of substance-related rule infractions by 1.5 times. The Nagelkerke's R squares for the models indicated that the 
independent variables explained $7.1 \%$ of the variation for major rule infractions, $5 \%$ for minor rule infractions, and $5.9 \%$ for substance-related rule infractions.

Table 9. Logistic Regression: Major, Minor and Substance-Related Rule Infractions.

\begin{tabular}{|c|c|c|c|c|c|c|c|c|c|}
\hline \multirow[t]{2}{*}{ Variables } & \multirow[b]{2}{*}{$\underline{b}$} & \multicolumn{2}{|c|}{$\begin{array}{l}\text { Major rule } \\
\text { infractions }\end{array}$} & \multicolumn{2}{|c|}{$\begin{array}{l}\text { Minor rule } \\
\text { infractions }\end{array}$} & \multicolumn{4}{|c|}{$\begin{array}{l}\text { Substance-related } \\
\text { rule infractions }\end{array}$} \\
\hline & & $\underline{\mathrm{SE}}$ & $\underline{\mathrm{OR}}$ & $\underline{\mathrm{B}}$ & $\underline{\mathrm{SE}}$ & $\underline{\mathrm{OR}}$ & $\underline{\mathrm{b}}$ & $\underline{\mathrm{SE}}$ & $\underline{\mathrm{OR}}$ \\
\hline Mental Illness & .180 & .132 & 1.197 & $.455 * * *$ & .133 & 1.577 & .078 & .128 & 1.082 \\
\hline Social Support & -.023 & .073 & .977 & -.075 & .074 & .928 & $.177 * *$ & .073 & 1.193 \\
\hline Age & $-.021 * *$ & .008 & .979 & $-.030 * * *$ & .008 & .971 & -.003 & .007 & .997 \\
\hline Income & $.010^{*}$ & .018 & 1.010 & .005 & .018 & 1.005 & .007 & .017 & 1.007 \\
\hline Black & $.420 * *$ & .152 & 1.522 & $.348^{*}$ & .156 & 1.417 & $-.606 * * *$ & .150 & .545 \\
\hline All Other Race & .311 & .211 & 1.365 & -.131 & .206 & .877 & -.142 & .200 & .868 \\
\hline Married & $-.431 *$ & .208 & .650 & -.187 & .196 & .829 & -.377 & .205 & .686 \\
\hline $\begin{array}{l}\text { Widowed/Separated/ } \\
\text { Divorced }\end{array}$ & $-.574 * * *$ & .172 & .563 & .105 & .167 & 1.111 & -.207 & .161 & .813 \\
\hline Education & .061 & .142 & 1.062 & .105 & .146 & 1.110 & $.365^{* *}$ & .134 & 1.440 \\
\hline Children & -.284 & .154 & .753 & -.276 & .172 & .759 & -.047 & .154 & .954 \\
\hline Drug use & -.010 & .022 & .990 & -.005 & .021 & .995 & -.005 & .020 & .995 \\
\hline $\begin{array}{l}\text { Length of Sentence } \\
\text { (Maximum) Years }\end{array}$ & .010 & .008 & 1.010 & .010 & .009 & 1.010 & $.028 * * *$ & .008 & 1.028 \\
\hline $\begin{array}{l}\text { Nagelkerke } \mathbf{R} \\
\text { Square }\end{array}$ & & .071 & & & .050 & & & .059 & \\
\hline
\end{tabular}

Note: $\mathrm{b}=$ coefficient; $\mathrm{SE}=$ robust standard error; $\mathrm{OR}=$ odds ratio/exp $(\mathrm{b}),{ }^{*} \mathrm{p}<.05 * * \mathrm{p}<.01,{ }^{* * *} \mathrm{P}<.001$

Table 10 shows the results of the logistic regression model for predicting major rule infractions split by mental illness status. Among inmates without mental health problems, social support increased the odds of a major rule infraction by 1.03 times. Among inmates who had experienced mental health problems, an increase in social support decreased the odds of a major rule infractions $(\mathrm{OR}=.927)$; however, neither of these trends were statistically significant. Among inmates who did not have mental health problems, increase in age significantly decreased the 
odds of a major rule infraction $(\mathrm{OR}=.975)$. Compared to the White group, being Black increased the odds of major rule infractions $(\mathrm{OR}=1.597)$ for inmates with mental health problems, whereas, being mixed race or all other race, increased the odds of major rule infractions $(\mathrm{OR}=1.360)$ for inmates without mental health problems. Compared to the nevermarried group, being married and Widowed/Separated/Divorced, decreased the odds of major rule infractions regardless of mental health problems. Being educated increased the odds of major rule infractions by 1.5 times for inmates without any mental health problems. There was no significant association between drug use and major rule infractions nor sentence length and major rule infractions regardless of mental illness conditions. Overall, taken as a set, the predictors in the group with mental illness accounts for only 7.0\% (Nagelkerke R Square $=.070)$, variations in major rule infractions. Whereas, predictors in the group without mental illness accounts for $10.3 \%($ Nagelkerke R Square $=.103)$ variations in major rule infractions.

Table 10. Logistic Regression for Major Rule Infractions Split by Mental Health Problems.

\begin{tabular}{lllllll}
\hline \multirow{2}{*}{ Variables } & \multicolumn{7}{c}{ Mental Illness } \\
& \multicolumn{2}{c}{ Yes } & \multicolumn{3}{c}{ No } \\
\hline Social Support & $b$ & $S E$ & OR & $b$ & $S E$ & OR \\
Age & -.076 & .098 & .927 & .029 & .112 & 1.029 \\
Income & -.021 & .011 & .980 & $-.025^{*}$ & .012 & .975 \\
Black & .031 & .024 & 1.032 & -.014 & .027 & .986 \\
All Other races & $.468^{*}$ & .206 & 1.597 & .262 & .232 & 1.300 \\
Married & .246 & .272 & 1.279 & .308 & .339 & 1.360 \\
Widowed/Separated/Divorced & -.143 & .267 & .867 & $-.908^{*}$ & .358 & .403 \\
Education & $-.593^{* *}$ & .231 & .553 & $-.522^{*}$ & .263 & .593 \\
Children & -.206 & .195 & .814 & .403 & .212 & 1.496 \\
Drug use & -.155 & .215 & .857 & -.427 & .228 & .653 \\
Length of sentence (maximum) & .011 & .027 & 1.011 & -.053 & .039 & .948 \\
years & .013 & .010 & 1.013 & .008 & .012 & 1.008 \\
Nagelkerke R Square & & & & & & \\
\hline
\end{tabular}


Note: $\mathrm{b}=$ coefficient; $\mathrm{SE}=$ robust standard error; $\mathrm{OR}=$ odds ratio/exp $(\mathrm{b}),{ }^{*} \mathrm{p}<.05 * * \mathrm{p}<.01,{ }^{* * *} \mathrm{P}<.001$

Table 11 shows the results of the logistic regression model for predicting minor rule infractions split by mental health problems. An increase in social support decreased the odds of minor rule infractions for inmates regardless of mental health problems. An increase in Age decreased the odds of minor rule infractions for inmates in both groups. With an increase in income, the odds of minor rule infractions increased by 1.08 times for inmates without any mental health problems. Compared to the White group, being Black significantly increased the odds of minor rule infractions by 1.59 times for inmates without any mental health problems. There were no other significant findings for minor rule infractions split by mental health problems on the other independent variables included in table 11. Overall, taken as a set, the predictors in the group with mental illness accounts for only $4.5 \%$ (Nagelkerke R Square $=$. 045), variations in minor rule infractions which is a moderate fit. Whereas, predictors in the group without mental illness account for $6.8 \%$ (Nagelkerke R Square $=.068)$ variations in minor rule infractions.

Table 11. Logistic Regression for Minor Rule Infractions Split by Mental Health Problems.

\begin{tabular}{lllllll}
\hline \multicolumn{1}{c}{ Variables } & \multicolumn{9}{c}{ Mental Illness } \\
& \multicolumn{2}{c}{ Yes } & \multicolumn{2}{c}{ No } \\
\hline Social Support & $b$ & $S E$ & OR & $b$ & $S E$ & OR \\
& -.056 & .107 & .946 & -.067 & .105 & .935 \\
Age & & & & & & \\
Income & $-.026^{*}$ & .011 & .974 & $-.033^{* *}$ & .011 & .968 \\
Black & $-.063^{*}$ & .026 & .939 & $.075^{* *}$ & .027 & 1.078 \\
All Other race & .274 & .230 & 1.316 & $.461^{*}$ & .217 & 1.586 \\
& -.228 & .273 & .797 & -.021 & .321 &
\end{tabular}

(Table continues) 
Table 11. (Continues)

\begin{tabular}{|c|c|c|c|c|c|c|}
\hline \multirow{3}{*}{ Variables } & \multicolumn{5}{|c|}{ Mental Illness } & \multirow[b]{3}{*}{ OR } \\
\hline & & Yes & & No & & \\
\hline & $b$ & $S E$ & OR & $b$ & $S E$ & \\
\hline Married & -.330 & .276 & .719 & -.037 & .286 & .963 \\
\hline Widowed/Separated/Divorced & .054 & .240 & 1.055 & .156 & .240 & 1.168 \\
\hline Education & .083 & .209 & 1.086 & .106 & .210 & 1.111 \\
\hline Children & -.269 & .252 & .764 & -.338 & .242 & .713 \\
\hline Drug use & .004 & .028 & 1.004 & -.020 & .034 & .981 \\
\hline $\begin{array}{l}\text { Length of sentence (maximum) } \\
\text { years }\end{array}$ & .008 & .013 & 1.008 & .011 & .012 & 1.011 \\
\hline Nagelkerke R Square & & .045 & & & .068 & \\
\hline
\end{tabular}

Note: $\mathrm{b}=$ coefficient; $\mathrm{SE}=$ robust standard error; $\mathrm{OR}=$ odds ratio/exp $(\mathrm{b}),{ }^{*} \mathrm{p}<.05 * * \mathrm{p}<.01,{ }^{* * *} \mathrm{P}<.001$

Table 12 shows the results of the logistic regression model for predicting substancerelated rule infractions split by mental health problems. An increase in social support, increased the odds of substance-related rule infractions by 1.23 times for inmates without mental health problems. But this find was not significant one. Compared to the White group, being Black significantly reduced the odds of substance-related rule infractions for inmates regardless of mental health problems. Being educated significantly increased the odds of substance-related rule infractions by 1.57 times for inmates without mental health problems. An increase in sentence length significantly increased the odds of substance-related rule infractions for inmates without mental health problems $(\mathrm{OR}=1.047)$. There were no other significant findings for minor rule infractions split by mental health problems on the other independent variables included in table 12. Overall, taken as a set, the predictors in the group with mental illness accounts for only $4.5 \%$ (Nagelkerke R Square $=.045)$, variations in substance-related rule infractions. Whereas, 
predictors in the group without mental illness accounts for only 10.2\% (Nagelkerke R Square $=$ .102) variations in substance-related rule infractions.

Table 12. Logistic Regression Model for Substance-Related Rule Infractions Split by Mental Health Problems.

\begin{tabular}{|c|c|c|c|c|c|c|}
\hline \multirow{3}{*}{ Variables } & \multicolumn{6}{|c|}{ Mental Illness } \\
\hline & \multicolumn{3}{|c|}{ Yes } & \multicolumn{3}{|c|}{ No } \\
\hline & $b$ & $S E$ & OR & $b$ & $S E$ & OR \\
\hline Social Support & .148 & .098 & 1.160 & .207 & .110 & 1.230 \\
\hline Age & -.011 & .010 & .990 & .003 & .011 & 1.003 \\
\hline Income & .031 & .023 & 1.031 & -.026 & .027 & .974 \\
\hline Black & $-.500^{*}$ & .207 & .607 & $-.779 * * *$ & .226 & .459 \\
\hline All Other race & .087 & .250 & 1.091 & -.512 & .342 & .599 \\
\hline Married & -.329 & .272 & .720 & -.450 & .320 & .637 \\
\hline Widowed/Separated/Divorced & -.096 & .214 & .908 & -.349 & .250 & .706 \\
\hline Education & .314 & .180 & 1.370 & $.449 *$ & .205 & 1.566 \\
\hline Children & .011 & .211 & 1.011 & -.108 & .231 & .898 \\
\hline Drug use & -.021 & .025 & .979 & .023 & .034 & 1.023 \\
\hline $\begin{array}{l}\text { Length of sentence (maximum) } \\
\text { years }\end{array}$ & .015 & .010 & 1.015 & $.046^{* * *}$ & .011 & 1.047 \\
\hline Nagelkerke R Square & & .045 & & & & .102 \\
\hline
\end{tabular}

Note: $\mathrm{b}=$ coefficient; $\mathrm{SE}=$ robust standard error; $\mathrm{OR}=$ odds ratio/exp(b), ${ }^{*} \mathrm{p}<.05 * * \mathrm{p}<.01,{ }^{* * *} \mathrm{P}<.001$ 


\section{CHAPTER V: DISCUSSION}

Descriptive analyses from table 2 show that a majority of the inmates in the sample were involved in minor rule infractions (74\%) and half of the inmates had mental health problems $(55 \%)$. The findings from the analyses show strong support for hypothesis 1 , which states that mental health problems increase rule infractions among female inmates. Findings from crosstab analyses of table 4 show that female inmates with mental health problems have significantly higher rates of minor rule infractions than inmates without any symptoms ( $78 \% \mathrm{vs} 70.5 \%$, respectively). Additionally, findings from the logistic regression model (table 9) provide more insight; mental illness conditions increase the odds of minor rule infractions among female inmates by 1.58 times. These findings are consistent with previous literature (Jiang, FisherGiorlando, \& Mo, 2005; Tewksbury, Connor, \& Denney, 2014; Negy, Woods, \& Carlson,1997; Steiner, \& Wooldredge, 2009).

On the other hand, there was no support for hypotheses 2, which states that social support variables reduce rule infractions among female inmates. Descriptive statistics from table 2 showed that, on an average, female inmates received 5 social support items out of 6 . But t-test results from table 8 shows that the average social support for inmates was no different for those with or without a substance-related rule infraction (5.1 vs. 4.94). Findings from the logistic regression model (table 9) show that social support increased the odds of substance-related rule infractions by 1.19 times. This contradicts some previous studies, where social support was found to decrease rule infractions (Jiang \& Winfree, 2006; Mancini et al., 2016; Pollock, 2002).

Similar to hypothesis 2 , there were no significant findings for hypothesis 3 . Though results presented in table 12 showed that regardless of mental health problems, the presence of social support increased the odds of substance-related rule infractions for female inmates. This is 
opposite to hypotheses 3 which states that the association between mental health problems and rule infractions will be reduced in the presence of social support. This finding contradicts Pearlin and colleague's (1981) stress model theory. The stress model explains that individuals look for various coping resources for avoiding or eliminating stress. For example, if an individual receives coping resources in the form of social supports, then the manifestation of the stress phase will have reduced negative outcome or reduced violence. While receiving social support in prison, participation in substance-related rule infractions provides evidence of the fact that the inmates are unable to cope with the rising level of stress. This provides significant concerns since stress and mental health literatures have been found significant role of social support to reduce violence among female inmates (Cullen, 1994; Jiang, Fisher-Giorlando, \& Mo, 2005; Jiang and Winfree, 2006; Silver \& Teasdale, 2005; Tewksbury \&Connor, 2012).

Nevertheless, the findings for hypotheses 2 and 3 also have roots in the literature. According to Lynch (2017), inmates' mental health problems are long-lasting which requires adequate attention over the time. Also, Lynch discussed that the improved mental health problems depend on the inmate's previous history of trauma exposure, abuse, and the difficulty of finding the right personnel with whom to talk. For example, if inmates receive visits by their domestic abusive partners, it is more likely that the inmates will be more stressed and consequently will end up violating rules. Based on Cullen's (1994) explanation, social support can reduce stress from emerging, only if the inmate feels connected with the available social support. Now the contradictory findings for hypotheses 2 and 3 explain that though social support was in place, inmates' feelings of connectedness for their family did not produce a mitigating effect on rule infractions. This also connects to the fact that stress and impaired social support might be the cause of increased violence or substance-related rule infractions (Silver \& 
Teasdale, 2005). Hence, the findings provide serious consideration for observing the quality of social support that the inmates are receiving in prison.

\section{Policy Implications}

The present study showed that $55 \%$ of the inmates in the study suffered from mental health problems. Considered another way, this indicates that the majority of women incarcerated in state correctional facilities in the U.S.A. are in need of mental health treatment. To create a supportive environment, the criminal justice system must be prepared to meet these emerging needs. More research is needed to fully understand the challenges of mental health problems in prison and ways to assist incarcerated populations. Future reforms in this area must include substantially increasing the number of skilled mental health professionals working with incarcerated people, as well as increasing funding for mental health programming.

\section{Limitations}

Using secondary data is not without its limitations. The researcher had to depend on the the data set of the 2004 Survey of Inmates in State Correctional Facilities (SISCF) for performing the statistical analysis. The operationalization of key variables posed significant limitations for this study. Although the researcher wanted to test a number of specific constructs, there were not always reasonable proxies in the original dataset. Accordingly, the researcher used available variables from the dataset for measuring moderating variables. For instance, the questionnaires for social support variables were measured differently throughout the survey. For measuring visitation, "And how often have you been personally visited by your child(ren)?" questionnaire provided 5 categorical options from 1 to 5 , whereas "Were you allowed to have any visits?" questionnaire provided yes or no options. 
Also, the researcher could not use key variables for measuring the impact of social support on rule infractions. For example, "How many visits have you had?" considered significant for measuring visitation but was removed from the analysis as the case had almost $66 \%$ missing data. One of the key limitations of this current study was handling irresponsive or missing data. In fact, the rule infractions variable had a large amount of missing data that needed to be revised by doing further statistical analysis. Without much deeper knowledge of the data skipping pattern, the researcher here cannot provide any potential explanations for data missingness. Moreover, this - and the limited time period for the analysis — precluded the researcher from exploring other options for missing data.

Another limitation of this study includes the timeline of the collected data as the data were collected in 2003. For instance, in the seventeen years that have passed since the data were collected, there may have been changes in socio-demographic variables like education, income level, children, and marital status which can cause a significant difference in the life of inmates and their social relations. Also, emerging awareness for the development of Crisis Intervention Training (CIT) or Crisis Intervention Partnership (CIP) training along with mental health courts may have changed the experiences of inmates suffering from mental health problems.

Despite limitations to external validity, this study is the first one to test the impact of social support variables on mental health problems for female inmates in state correctional facilities. The role of social support for intervening rule infractions does represent the potential value for the study. Overall, the findings can be insightful to make a meaningful contribution to the field of mental health and criminal justice literature. 


\section{Recommendations}

Findings from the study can serve as a foundation for future research to look deeper into the impact of social support on female inmates and mental health problems. Since this study was conducted within a limited time frame, multiple imputation techniques were not a practicable solution. Hence, the researcher recommends applying multiple imputation techniques to handle missing data. Moreover, future studies should include more detailed information on the types and frequency of social support variables to avoid any missing data limitations.

Additionally, findings from table 3 shows that inmates with children reported significantly higher rates of major rule infractions compared to inmates without children (35.4\% vs $24.9 \%$ ). This is opposite to Owen's study (1998), as Owen explained that female inmates survive prison life aiming to reunite with their children. Whereas, by committing major rule infractions the chance of reuniting becomes smaller. Also, one of the findings shows that married inmates have a similar rate of involvement for substance-related rule infractions compared to widowed/separated/divorced and never-married individuals ( $24.9 \%$ vs. $30.6 \%$ vs. $30.8 \%)$. These findings give newer directions to future research since marriage has always been regarded as a controlling factor for rule infractions (Jiang and colleagues, 2005; Jiang and Winfree, 2006). Therefore, findings from the study can pave the way for future studies to discover more underlying challenges for female inmates. Future studies need to incorporate social support variables to understand the role of stress and mental health problems for female inmates in prison. 


\section{REFERENCES}

Abram, K. M., Teplin, L. A., \& McClelland, G. M. (2003). Comorbidity of severe psychiatric disorders and substance use disorders among women in jail. American Journal of Psychiatry, 160(May), 1007-1010.

Acevedo, K. C., \& Bakken, T. (2001). The effects of visitation on women in prison. International Journal of Comparative and Applied Criminal Justice, 25(1), 4969.

Acevedo, K. C., \& Bakken, T. (2003). Women adjusting to prison: Disciplinary behavior and the characteristics of adjustment. Journal of Health and Social Policy, 17(4), 37-60.

Adams, K. (1986). The disciplinary experiences of mentally disordered inmates. Criminal Justice and Behavior, 13(3), 297-316.

Alexopoulos, E. C. (2010). Introduction to multivariate regression analysis. Hippokratia, 14 (Suppl 1), 23-28.

Bales, W. D., \& Miller, C. H. (2012). The impact of determinate sentencing on prisoner misconduct. Journal of Criminal Justice, 40(5), 394-403.

Banauch, P.J. (1985). Mothers in Prison. New Brunswick: Transaction Books.

Bennet, J. A. (2000). Focus on research methods mediator and moderator variables. Nursing Research: Conceptual and Statistical Differences, School of Nursing, San Diego State University, San Diego, CA. 
Bloom, B. E., \& Covington, S. (2008). Addressing the mental health needs of women offenders. Women's mental health issues across the criminal justice system, 160-176.

Bloom, B., Chesney-Lind, M., \& Owen, B. (1994). Women in California prisons. San Francisco: Center on Juvenile and Criminal Justice.

Borgman, R. (1985). Influence of family visiting upon boys' behavior in a juvenile correctional institution. Child Welfare, 64, 629-638.

Braxton-Mintz, R. (2009). Inmate programs: A tool for managing behavior. Corrections Today, 71(6), 100-101.

Broidy, L. M. (2001). A test of general strain theory. Criminology, 39(1), 9-36.

Bronson, J., \& Berzofsky, M. (2017). Indicators of mental health problems reported by prisoners and jail inmates, 2011-12. Bureau of Justice Statistics, 1-16.

Bronson, J., Stroop, J., Zimmer, S., \& Berzofsky, M. (2017). Drug use, dependence, and abuse among state prisoners and jail inmates, 2007-2009. Washington, DC: United States Department of Justice, Office of Juvenile Justice and Delinquency Prevention.

Browne, A., Miller, B., \& Maguin, E. (1999). Prevalence and severity of lifetime physical and sexual victimization among incarcerated women. International journal of law and psychiatry, 22,301-322.

Camp, S.D., Gaes, G.G., Langan, N.P., \& Saylor, W.G. (2003). The influence of prisons on inmate misconduct: A multilevel investigation. Justice Quarterly, 20, 501-533. 
Cao, L., Zhao, J., \& Van Dine, S. (1997). Prison disciplinary tickets: A test of the deprivation and importation models. Journal of Criminal Justice, 25, 103-113.

Carroll, L. (1974). Hacks, blacks, and cons: Race relations in a maximum-security prison. Lexington, MA: Lexington Books.

Carson, E. A., \& Golinelli, D. (2012). Prisoners in 2012-advance counts. Washington, DC: Bureau of Justice Statistics, U.S. Department of Justice.

Casey-Acevedo, K., \& Bakken, T. (2001). The effect of time on the disciplinary adjustment of women in prison. International Journal of Offender Therapy and Comparative Criminology, 45(4), 489-497.

Casey-Acevedo, K., \& Bakken, T. (2002). Visiting women in prison: Who visits and who cares? Journal of Offender Rehabilitation, 34(3), 67-83.

Casey-Acevedo, K., Bakken, T., \& Karle, A. (2004). Children visiting mothers in prison: The effects on mothers' behaviour and disciplinary adjustment. Australian \& New Zealand Journal of Criminology, 37(3), 418-430.

Celinska, K., \& Sung, H. E. (2014). Gender differences in the determinants of prison rule violations. The Prison Journal, 94(2), 220-241.

Christian, J. (2005). Riding the bus: Barriers to prison visitation and family management strategies. Journal of Contemporary Criminal Justice, 21(1), 31-48.

Cihan, A., Davidson, M., \& Sorensen, J. (2017). Analyzing the heterogeneous nature of inmate behavior: Trajectories of prison misconduct. The Prison Journal, 97(4), 431-450. 
Clone, S., \& DeHart, D. (2014). Social support networks of incarcerated women: Types of support, sources of support, and implications for reentry. Journal of Offender Rehabilitation, 53(7), 503-521.

Coelho, G.V., Hamburg, D.A., \& Adams, J.E. (1974). Coping and Adaptation. New York: Basic Books

Cohen, S., \& Wills, T. A. (1985). Stress, social support, and the buffering hypothesis. Psychological bulletin, 98(2), 310-357.

Covington, S. S. (2007). Women and the criminal justice system. Women's Health Issues, 17(4), 180-182.

Covington, S. S., \& Bloom, B. E. (2003). Gendered justice: Women in the criminal justice system. Gendered justice: Addressing female offenders, 3-23.

Craddock, A. (1996). A comparative study of male and female prison misconduct careers. The Prison Journal, 76, 60-80.

Cullen, F. T. (1994). Social support as an organizing concept for criminology: Presidential address to the Academy of Criminal Justice Sciences. Justice Quarterly, 11(4), 527559.

Cullen, F. T., Wright, J. P., \& Chamblin, M. B. (1999). Social support and social reform: A progressive crime control agenda. Crime \& Delinquency, 45, 188-207

Cunningham, M. D., \& Sorensen, J. R. (2006). Nothing to lose? A comparative examination of prison misconduct rates among life-without-parole and other long-term high-security inmates. Criminal Justice and Behavior, 33, 683-705. 
DeHart, D., Lynch, S., Belknap, J., Dass-Brailsford, P., \& Green, B. (2014). Life history models of female offending: The roles of serious mental illness and trauma in women's pathways to jail. Psychology of Women Quarterly, 38(1), 138-151.

Fazel, S., Hayes, A. J., Bartellas, K., Clerici, M., \& Trestman, R. (2016). Mental health of prisoners: prevalence, adverse outcomes, and interventions. The Lancet Psychiatry, 3(9), 871-881.

Fellner, J. (2006). A corrections quandary: Mental illness and prison rules. Harv. CR-CLL Rev., 41, 391-412.

Felson, R. B., Silver, E., \& Remster, B. (2012). Mental disorder and offending in prison. Criminal Justice and Behavior, 39(2), 125-143.

Flanagan, T. J. (1983). Correlates of institutional misconduct among state prisoners: A research note. Criminology, 21, 29-39.

Fogel, C. I., Martin, S. L., Anderson, N. L., Murphy, S. A., \& Dickson, L. A. S. (1992). The mental health of incarcerated women. Western Journal of Nursing Research, 14(1), 3047.

Fogel, C.I. (1993). Hard time: The stressful nature of incarceration on women. Issues in Mental Health Nursing, 14, 367-377.

Fogel, C.I., \& Martin S. (1992). Mental health of incarcerated women. Western Journal of Nursing Research, 14, 30-47.

Frey, J. H., \& Delaney, T. (1996). The role of leisure participation in prison: A report from consumers. Journal of Offender Rehabilitation, 23(1-2), 79-89. 
Gendreau, P., Goggin, C.E., \& Law, M.A. (1997). Predicting prison misconducts. Criminal Justice and Behavior, 24, 414-431.

Glaze, L. E., \& Herberman, E. J. (2013). Correctional populations in the United States, 2012. Washington, DC: Bureau of Justice Statistics, U.S. Department of Justice.

Goffman, E. (1961). Asylums: Essays on the social situation of mental patients and other inmates. Aldine Transaction. Garden City, NY: Doubleday.Goodstein, L., MacKenzie, D. L., \& Shotland, R. L. (1984). Personal control and inmate adjustment to prison. Criminology, 22(3), 343-369.

Gover, A. R., Pe'rez, D. M., \& Jennings, W. G. (2008). Gender differences in factors contributing to institutional misconduct. The Prison Journal, 88, 378-403.

Graham, J. W. (2009). Missing data analysis: Making it work in the real world. Annual Review of Psychology, 60, 549-576.

Green, B. L., Miranda, J., Daroowalla, A., \& Siddique, J. (2005). Trauma exposure, mental health functioning, and program needs of women in jail. Crime \& Delinquency, 51(1), $133-151$.

Griffin, M. L., \& Hepburn, J. R. (2006). The effect of gang affiliation on violent misconduct among inmates during the early years of confinement. Criminal Justice and Behavior, $33,419-448$.

Hairston, C.F. (1988). Family ties during imprisonment: Do they influence future criminal activity? Federal Probation, 88, 48-52. 
Harer, M. D., \& Langan, N. P. (2001). Gender differences in predictors of prison violence: Assessing the predictive validity of a risk classification system. Crime $\&$ Delinquency, 47(4), 513-536.

Harer, M. D., \& Steffensmeier, D. J. (1996). Race and prison violence. Criminology, 34, 323355.

Hart, C. B. (1995). Gender differences in social support among inmates. Women \& Criminal Justice, 6(2), 67-88.

Henriques, Z. W. (1982). Imprisoned mothers and their children: A descriptive and analytical study. Washington, DC: University Press of America.

Hensley, C., Koscheski, M., \& Tewksbury, R. (2002). Does participation in conjugal visitations reduce prison violence in Mississippi? An exploratory study. Criminal Justice Review, $27,53-65$.

Houser, K. A., Belenko, S., \& Brennan, P. K. (2012). The effects of mental health and substance abuse disorders on institutional misconduct among female inmates. Justice Quarterly, 29(6), 799-828.

Huebner, B. M. (2003). Administrative determinants of inmate violence: A multilevel analysis. Journal of Criminal Justice, 31(2), 107-117.

Hurley, W., \& Dunne, M. P. (1991). Psychological distress and psychiatric morbidity in women prisoners. Australian \& New Zealand Journal of Psychiatry, 25(4), 461-470.

Irwin, J. K. (1981). Sociological studies of the impact of long-term confinement. Confinement in maximum custody. Lexington, MA: DC Heath. 
Irwin, J., \& Cressey, D. R. (1962). Thieves, convicts and the inmate culture. Social Problems, $10(2), 142-155$.

Irwin, J. (1970). 1970 The Felon. Englewood Cliffs, NJ: Prentice-Hall.

Irwin, J., \& Cressey, D. R. (1962). Thieves, convicts and the inmate culture. Social problems, 10(2), 142-155.

James, D. J. (2004). Profile of jail inmates 2002. Washington, DC: U.S. Department of Justice, Office of Justice Programs, Bureau of Justice Statistics.

James, D. J., \& Glaze, L. E. (2006). Mental health problems of prison and jail inmates. Washington, DC: Bureau of Justice Statistics.

Jiang, S., \& Winfree Jr, L. T. (2006). Social support, gender, and inmate adjustment to prison life: Insights from a national sample. The Prison Journal, 86(1), 32-55.

Jiang, S., Fisher-Giorlando, M., \& Mo, L. (2005). Social support and inmate rule violations: A multilevel analysis. American Journal of Criminal Justice, 30(1), 71-86.

Jones, R. S. (1993). Coping with separation: Adaptive responses of women prisoners. Women \& Criminal Justice, 5(1), 71-97.

Jordan, B. K., Schlenger, W. E., Fairbank, J. A., \& Caddell, J. M. (1996). Prevalence of psychiatric disorders among incarcerated women: II. Convicted felons entering prison. Archives of General Psychiatry, 53(6), 513-519.

Kaiser, J. (2014). Dealing with missing values in data. Journal of systems integration, 5(1), 4251. 
Kajstura, Aleks. (October 29, 2019). Women's Mass Incarceration: The whole pie 2019. Retrieved from: https://www.prisonpolicy.org/reports/pie2019women.html

Kawachi, I., \& Berkman, L. F. (2001). Social ties and mental health. Journal of Urban health, 78(3), 458-467.

Krelstein, M. S. (2002). The role of mental health in the inmate disciplinary process: a national survey. Journal of the American Academy of Psychiatry and the Law Online, 30(4), 488-496.

Kruttschnitt, C., \& Gartner, R. (2005). Marking time in the golden state: Women's imprisonment in California. Cambridge University Press.

Kuanliang, A., \& Sorensen, J. (2008). Predictors of self $\square$ reported prison misconduct. Criminal Justice Studies, 21(1), 27-35.

Kuanliang, A., Sorensen, J. R., \& Cunningham, M. D. (2008). Juvenile inmates in an adult prison system: Rates of disciplinary misconduct and violence. Criminal Justice and Behavior, 35, 1186-1201.

Kuo, S. Y., \& Zhao, R. (2019). Prison misconduct among female inmates with mental disorders, substance abuse/dependence, and co-occurring disorders in Taiwan. International Journal of Comparative and Applied Criminal Justice, 43(3), 263-276.

Lin, N. (1986). Conceptualizing social support social support, life events, and depression (pp. 17-30). Orlando, FL: Academic Press. 
Lindquist, C. H., \& Lindquist, C. A. (1997). Gender differences in distress: Mental health consequences of environmental stress among jail inmates. Behavioral Sciences \& the Law, 15(4), 503-523.

Lynch, S. M., Fritch, A., \& Heath, N. M. (2012). Looking beneath the surface: The nature of incarcerated women's experiences of interpersonal violence, treatment needs, and mental health. Feminist Criminology, 7(4), 381-400.

MacKenzie, D. L., \& Goodstein, L. I. (1985). Long-term incarceration impacts and characteristics of long-term offenders: An empirical analysis. Criminal Justice and Behavior, 12, 395-414.

MacKenzie, D. L., Robinson, J. W., \& Campbell, C. S. (1989). Long-term incarceration of female offenders: Prison adjustment and coping. Criminal Justice and Behavior, 16(2), 223-238.

Malarvizhi, M. R., \& Thanamani, A. S. (2012). K-nearest neighbor in missing data imputation. International Journal of Engineering Research and Development, 5(1), 5-7.

Mancini, C., Baker, T., Sainju, K. D., Golden, K., Bedard, L. E., \& Gertz, M. (2016).

Examining external support received in prison and concerns about reentry among incarcerated women. Feminist Criminology, 11(2), 163-190.

Marcum, C. D., Hilinski-Rosick, C. M., \& Freiburger, T. L. (2014). Examining the correlates of male and female inmate misconduct. Security Journal, 27(3), 284-303.

Martin, M. E., \& Hesselbrock, M. N. (2001). Women prisoners' mental health: Vulnerabilities, risks and resilience. Journal of offender rehabilitation, 34(1), 25-43. 
McClellan, D. S. (1994). Disparity in the discipline of male and female inmates in Texas prisons. Women and Criminal Justice, 5, 71-97.

McCorkle, R. C., Miethe, T. D., \& Drass, K. A. (1995). The roots of prison violence: A test of the deprivation, management, and "not-so-total" institution models. Crime \& Delinquency, 41(3), 317-331.

McCorkle, R. C. (1995). Gender, psychopathology, and institutional behavior: A comparison of male and female mentally ill prison inmates. Journal of Criminal Justice, 23(1), 53-61.

McReynolds, L. S., \& Wasserman, G. A. (2008). Risk for disciplinary infractions among incarcerated male youths: Influence of psychiatric disorder. Criminal Justice and Behavior, 35, 1174-1185.

McShane, M. D., \& Williams, F. P. (1990). Old and ornery: The disciplinary experiences of elderly prisoners. International Journal of Offender Therapy \& Comparative Criminology, 34, 197-212.

Merbitz, C., Jain, S., Good, G. L., \& Jain, A. (1995). Reported head injury and disciplinary rule infractions in prison. Journal of Offender Rehabilitation, 22(3-4), 11-19.

Metzner, J. L. (2002). Commentary: The role of mental health in the inmate disciplinary process. Journal of the American Academy of Psychiatry and the Law Online, 30(4), 497-499.

Morris, R. G., Longmire, D. R., Buffington-Vollum, J., \& Vollum, S. (2010). Institutional misconduct and differential parole eligibility among capital inmates. Criminal Justice and Behavior, 37, 417-438. 
Myers, L. B., \& Levy, G. W. (1978). Description and prediction of the intractable inmate. Journal of Research in Crime and Delinquency, 15(2), 214-228.

Negy, C., Woods, D. J., \& Carlson, R. (1997). The relationship between female inmates' coping and adjustment in a minimum-security prison. Criminal Justice and Behavior, 24(2), 224-233.

Owen, B. A. (1998). In the mix: Struggle and survival in a women's prison. SUNY Press.

Owen, B., Wells, J., \& Pollock, J. (2017). In search of safety: Confronting inequality in women's imprisonment (Vol. 3). Oakland, CA: University of California Press.

Pearlin, L. I., Menaghan, E. G., Lieberman, M. A., \& Mullan, J. T. (1981). The stress processes. Journal of Health and Social behavior, 22, 337-356.

Petersilia, J., and Honig, P. (1980). The prison experience of career criminals. Santa Monica, CA: Rand Corporation.

Pollock, J. M. (2002). Women, crime, and prison. Belmont, CA: Wadsworth.

Poole, E. D., \& Regoli, R. M. (1979). Race, institutional rule breaking, and disciplinary response: A study of discretionary decision making in prison. Law \& Society Review, 14, 931-946.

Poole, E. D., \& Regoli, R. M. (1980). Race institutional rule breaking, and disciplinary response: A study of discretionary decision making in prison. Law \& Society Review, 14, 931-946. 
Reidy, T. J., \& Sorensen, J. R. (2018). The influence of sentence length on the commission of serious and violent prison infractions by female inmates. Criminal Justice and Behavior, 45(9), 1420-1434.

Reidy, T. J., Cihan, A., \& Sorensen, J. R. (2017). Women in prison: Investigating trajectories of institutional female misconduct. Journal of criminal justice, 52, 49-56.

Ruback, R. B., \& Carr, T. S. (1984). Crowding in a Woman's Prison: Attitudinal and Behavioral Effects 1. Journal of Applied Social Psychology, 14(1), 57-68.

Ryan, T. A., \& McCabe, K. A. (1994). Mandatory versus voluntary prison education and academic achievement. The Prison Journal, 74(4), 450-461.

Schnittker, J., Massoglia, M., \& Uggen, C. (2012). Out and down: Incarceration and psychiatric disorders. Journal of Health and Social Behavior, 53(4), 448-464.

Siennick, S. E., Mears, D. P., \& Bales, W. D. (2013). Here and gone: Anticipation and separation effects of prison visits on inmate infractions. Journal of Research in Crime and Delinquency, 50(3), 417-444.

Silver, E. (2002). Mental disorder and violent victimization: the mediating role of involvement in conflicted social relationships. Criminology, 40(1), 191-212.

Silver, E., \& Teasdale, B. (2005). Mental disorder and violence: An examination of stressful life events and impaired social support. Social Problems, 52(1), 62-78.

Simon, L. M. (1993). Prison behavior and the victim-offender relationship among violent offenders. Justice Quarterly, 10(3), 489-506. 
Snyder, Z. K., Carlo, T. A., \& Mullins, M. M. C. (2002). Parenting from prison: An examination of a children's visitation program at a women's correctional facility. Marriage \& Family Review, 32(3-4), 33-61.

Sorensen, J., \& Cunningham, M. D. (2010). Conviction offense and prison violence: A comparative study of murderers and other offenders. Crime \& Delinquency, 56, 103125.

Sorensen, J., Wrinkle, R., \& Gutierrez, A. (1998). Patterns of rule-violating behaviors and adjustment to incarceration among murderers. The Prison Journal, 78(3), 222-231.

Stacer, M. J., \& Solinas-Saunders, M. (2015). Physical and verbal assault behind bars: Does military experience matter? The Prison Journal, 95(2), 199-222.

Stanton, A. M. (1980). When mothers go to jail. Lexington, MA: Lexington Books.

Steadman, H. J., Osher, F. C., Robbins, P. C., Case, B., \& Samuels, S. (2009). Prevalence of serious mental illness among jail inmates. Psychiatric services, 60(6), 761-765.

Steiner, B., \& Wooldredge, J. (2008). Inmate versus environmental effects on prison rule violations. Criminal Justice and Behavior, 35(4), 438-456.

Steiner, B., \& Wooldredge, J. (2009). Individual and environmental effects on assaults and nonviolent rule breaking by women in prison. Journal of Research in Crime and Delinquency, 46(4), 437-467.

Steiner, B., Butler, H. D., \& Ellison, J. M. (2014). Causes and correlates of prison inmate misconduct: A systematic review of the evidence. Journal of Criminal Justice, 42(6), $462-470$. 
Steiner, B., Wright, E. M., \& Toto, S. (2019). The sources of violent and nonviolent offending among women in prison. Justice Quarterly, 1-23.

Stephan, J. J. (1990). Prison rule violators. US Department of Justice, Office of Justice Programs, Bureau of Justice Statistics.

Stewart, L. A., \& Wilton, G. (2014). Correctional outcomes of offenders with mental disorders. Criminal Justice Studies, 27(1), 63-81.

Stroud, L. R., Salovey, P., \& Epel, E. S. (2002). Sex differences in stress response: Social rejection versus achievement stress. Biological Psychiatry, 52, 318-327.

Sykes, G. (1958). The pains of imprisonment. The society of captives: A study of a maximumsecurity prison, 63-78.

Tahamont, S. (2019). The effect of facility security classification on serious rules violation reports in California prisons: a regression discontinuity design. Journal of Quantitative Criminology, 35(4), 767-796.

Taylor, S. E., Klein, L. C., Lewis, B. P., Grunewald, T. L., Gurung, R. A. R., \& Updegraff, J. A. (2000). Biobehavioral responses to stress in females: Tend-and-befriend, not fightor-flight. Psychological Review, 107, 411-429.

Teasdale, B., Daigle, L. E., Hawk, S. R., \& Daquin, J. C. (2016). Violent victimization in the prison context: An examination of the gendered contexts of prison. International journal of offender therapy and comparative criminology, 60(9), 995-1015.

Teasdale, B., Silver, E., \& Monahan, J. (2006). Gender, threat/control-override delusions and violence. Law and Human Behavior, 30(6), 649. 
Teplin, L. A. (1990). The prevalence of severe mental disorder among male urban jail detainees: comparison with the Epidemiologic Catchment Area Program. American Journal of Public Health, 80(6), 663-669.

Tewksbury, R., \& Connor, D. P. (2012). Inmates who receive visits in prison: Exploring factors that predict. Fed. Probation, 76, 43-46.

Tewksbury, R., Connor, D. P., \& Denney, A. S. (2014). Disciplinary infractions behind bars: An exploration of importation and deprivation theories. Criminal Justice Review, 39(2), 201-218.

Thoits, P. A. (1986). Social support as coping assistance. Journal of consulting and clinical psychology, 54(4), 416-423.

Thompson, C., \& Loper, A. B. (2005). Adjustment patterns in incarcerated women: An analysis of differences based on sentence length. Criminal Justice and Behavior, 32(6), 714-732.

Tischler, C. A., \& Marquart, J. W. (1989). Analysis of disciplinary infraction rates among female and male inmates. Journal of Criminal Justice, 17(6), 507-513.

Toch, H., \& Adams, K. (1986). Pathology and disruptiveness among prison inmates. Criminal Justice and Behavior, 23, 7-21.

Toch, H., \& Adams, K. (2002). Acting out: Maladaptation in prisons. Washington, DC: American Psychological Association Books.

Toch, H., Adams, K., \& Grant, J. D. (1989). Coping: Maladaptation in prisons. New Brunswick, NJ: Transaction Publishing. 
Toman, E. L. (2019). The victim-offender overlap behind bars: Linking prison misconduct and victimization. Justice Quarterly, 36(2), 350-382.

Toman, E. L., Cochran, J. C., Cochran, J. K., \& Bales, W. D. (2015). The implications of sentence length for inmate adjustment to prison life. Journal of Criminal Justice, 43(6), $510-521$.

Torrey, E. F., Kennard, A. D., Eslinger, D., Lamb, R., \& Pavle, J. (2010). More mentally ill persons are in jails and prisons than hospitals: A survey of the states. Arlington, VA: Treatment Advocacy Center, 1-18.

Travis, J., Western, B., \& Redburn, F. S. (2014). The growth of incarceration in the United States: Exploring causes and consequences. Washington, DC: National Academies Press.

Trestman, R. L., Ford, J., Zhang, W., \& Wiesbrock, V. (2007). Current and lifetime psychiatric illness among inmates not identified as acutely mentally ill at intake in Connecticut's jails. Journal of the American Academy of Psychiatry and the Law Online, 35(4), 490500.

Turner, R. J., \& Lloyd, D. A. (1999). The stress process and the social distribution of depression. Journal of Health and Social Behavior, 374-404. 
Tyner, A., Higgins, M., Malisz, D., Newton, E., Peterson, N., \& West, S. (2014). Phone Calls Creating Lifelines for Prisoners and Their Families: A Retrospective Case Study on the Campaign for Prison Phone Justice in Minnesota. Trinity Law Review, 20, 83-84.US Department of Justice, Bureau of Justice Statistics. (2004). Survey of inmates in state and federal correctional facilities, 2004.

Vaux, A. (1988). Social support: Theory, research, and intervention. Praeger publishers.

Walters, G. D. (2015). Criminal thinking as a predictor of prison misconduct and mediator of the static risk-infractions relationship. The Prison Journal, 95(3), 353-369.

Ward, D. A., \& Kassebaum, G. G. (1966). Women's prison: Sex and social structure. Chicago: Aldine.

Warren, J. I., Burnette, M. L., South, S. C., Chauhan, P., Bale, R., Friend, R., \& Van Patten, I. (2003). Psychopathy in women: Structural modeling and comorbidity. International Journal of Law and Psychiatry, 26(3), 223-242.

Warren, J. I., Hurt, S., Loper, A. B., \& Chauhan, P. (2004). Exploring prison adjustment among female inmates: Issues of measurement and prediction. Criminal Justice and Behavior, 31(5), 624-645.

Welsh, W. N., McGrain, P., Salamatin, N., \& Zajac, G. (2007). Effects of prison drug treatment on inmate misconduct: A repeated measures analysis. Criminal Justice and Behavior, $34,600-615$. 
Wooldredge, J., Griffin, T., \& Pratt, T. (2001). Considering hierarchical models for research on inmate behavior: Predicting misconduct with multilevel data. Justice Quarterly, 18, 203-231.

Woolredge, J. D. (1994). Inmate crime and victimization in a southwestern correctional facility. Journal of Criminal Justice, 22, 367-381.

Wright, E. M., Salisbury, E. J., \& Van Voorhis, P. (2007). Predicting the prison misconducts of women offenders: The importance of gender-responsive needs. Journal of Contemporary Criminal Justice, 23(4), 310-340.

Wright, K. N. (1991). A study of individual, environmental, and interactive effects in explaining adjustment to prison. Justice Quarterly, 8, 217-242.

Zamble, E. (1992). Behavior and adaptation in long-term prison inmates: Descriptive longitudinal results. Criminal Justice and Behavior, 19(4), 409-425.

Zingraff, M. T. (1980). Inmate assimilation: A comparison of male and female delinquents. Criminal Justice and Behavior, 7, 275-292. 